Portland State University

PDXScholar

Summer 10-3-2013

\title{
Evaluation of Phase Change Materials for Cooling in a Super-Insulated Passive House
}

Jeffrey Stephen Lauck

Portland State University

Follow this and additional works at: https://pdxscholar.library.pdx.edu/open_access_etds

Part of the Construction Engineering Commons, Engineering Science and Materials Commons, Environmental Design Commons, and the Natural Resources and Conservation Commons Let us know how access to this document benefits you.

\section{Recommended Citation}

Lauck, Jeffrey Stephen, "Evaluation of Phase Change Materials for Cooling in a Super-Insulated Passive House" (2013). Dissertations and Theses. Paper 1444.

https://doi.org/10.15760/etd.1443

This Thesis is brought to you for free and open access. It has been accepted for inclusion in Dissertations and Theses by an authorized administrator of PDXScholar. Please contact us if we can make this document more accessible: pdxscholar@pdx.edu. 
Evaluation of Phase Change Materials for Cooling in a Super-Insulated Passive House

\author{
by \\ Jeffrey Stephen Lauck
}

A thesis submitted in partial fulfillment of the requirements for the degree of

\author{
Master of Science \\ in \\ Mechanical Engineering
}

Thesis Committee:

David Sailor, Chair

Huafen $\mathrm{Hu}$

Graig Spolek

Portland State University

2013 
(C) 2013 Jeffrey Stephen Lauck 


\begin{abstract}
Due to factors such as rising energy costs, diminishing resources, and climate change, the demand for high performance buildings is on the rise. As a result, several new building standards have emerged including the Passive House Standard, a rigorous energy-use standard based on a super-insulated and very tightly sealed building envelope. The standard requires that that air infiltration is less than or equal to 0.6 air changes per hour at a 50 Pascal pressure difference, annual heating energy is less than or equal to $15 \mathrm{kWh} / \mathrm{m} 2$, and total annual source energy is less than or equal to $120 \mathrm{kWh} / \mathrm{m} 2$. A common complaint about passive houses is that they tend to overheat. Prior research using simulation suggests that the use of Phase Change Materials (PCMs), which store heat as they melt and release heat as the freeze, can reduce the number of overheated hours and improve thermal comfort.

In this study, an actual passive house duplex in Southeast Portland was thoroughly instrumented to monitor various air and surface temperatures. One unit contains $130 \mathrm{~kg}$ of PCM while the other unit contains no PCM to serve as an experimental control. The performance of the PCM was evaluated through analysis of observed data and through additional simulation using an EnergyPlus model validated with observed data. The study found that installation of the PCM had a positive effect on thermal comfort, reducing the estimated overheated hours from about 400 to 200 .
\end{abstract}




\section{Dedication}

I dedicate this thesis to my wife, Julie, who inspired me to follow my dreams and has offered continual support and encouragement throughout the process. 


\section{Acknowledgments}

Foremost, I would like to express my sincere gratitude to my advisor and committee chair, David Sailor, for his continual support and guidance. I would also like to thank my committee members, Huafen Hu and Graig Spolek, for their support and feedback.

I would like to thank Ella Wong, Randy Hayslip, Rob Hawthorne, Bart Berquist, and Matt Groves for their support and guidance throughout the project.

Special thanks to Phase Change Energy Solutions and Thermotech Fiberglass Fenestration for providing technical data and support.

Finally, I'd like to thank the students and faculty of the Green Building Research Laboratory, especially Santiago Rodriguez, Christophe Parroco, Daeho Kang, Pamela Wallace, Stephanie Jacobsen, and Steve Gross for their assistance with instrument installation, energy modeling, and data analysis.

This research is supported by the US Department of Energy under award DEEE0003870. 


\section{Table of Contents}

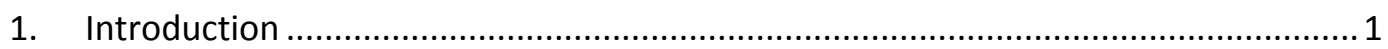

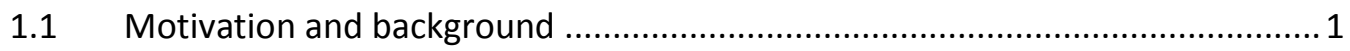

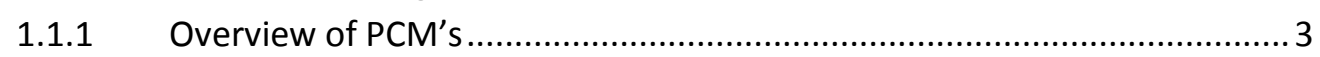

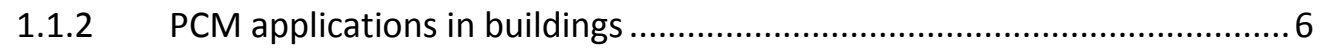

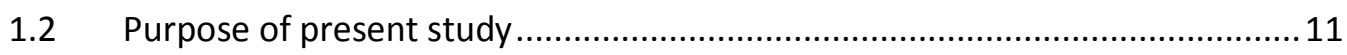

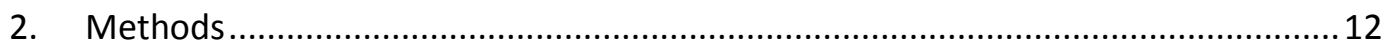

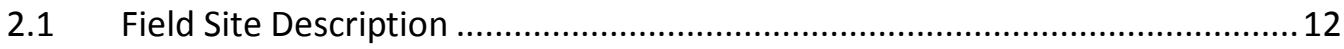

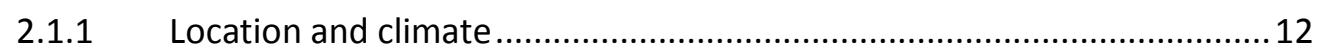

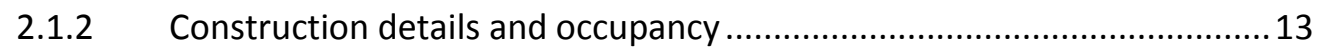

2.1.3 Instrumentation and data collection ....................................................... 18

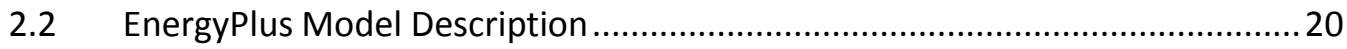

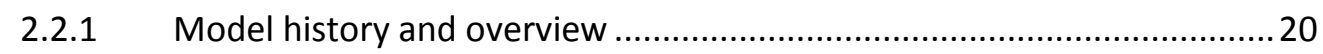

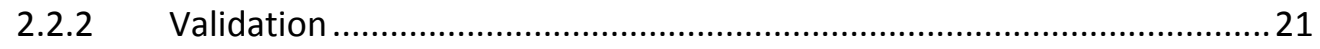

2.2.3 Major components, assumptions, and limitations ................................32

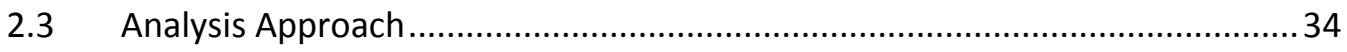

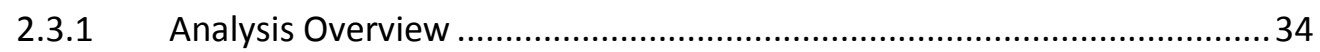

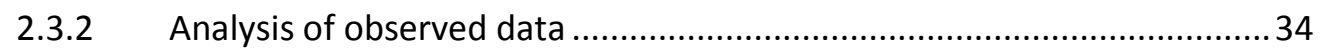

2.3.3 PCM experimentation with validated energy model................................34

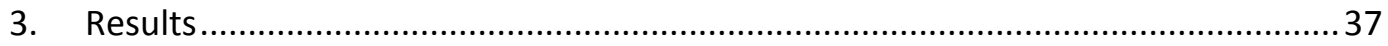

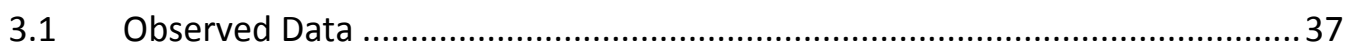

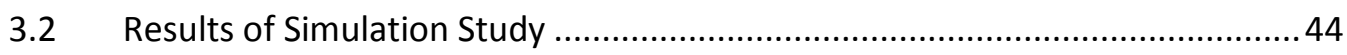

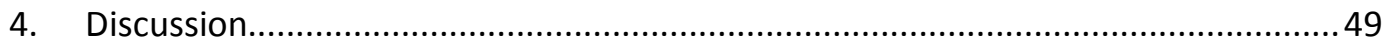

4.1 PCM performance - measured and modeled................................................49

4.1.1 Analysis of Observed Data ................................................................. 49

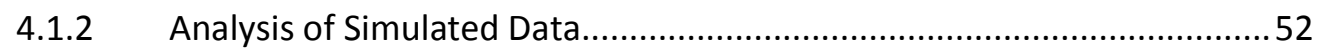

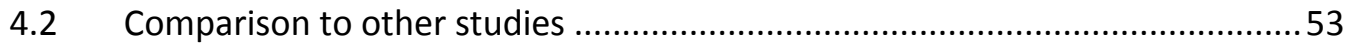

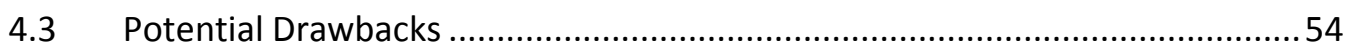

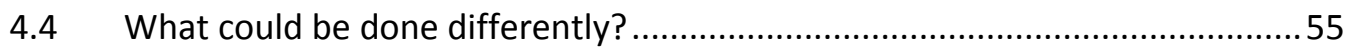

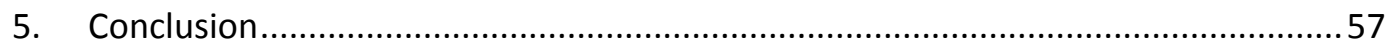

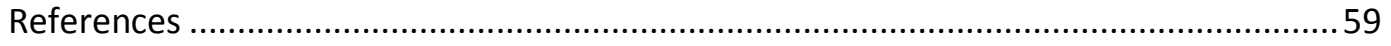




\section{List of Tables}

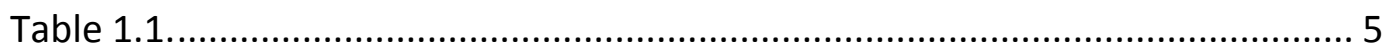

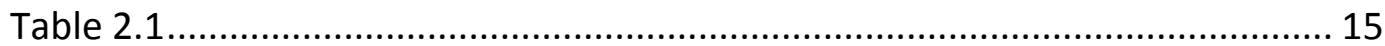

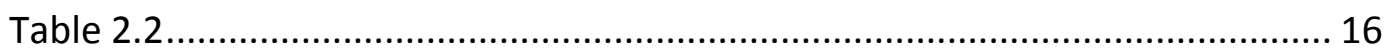

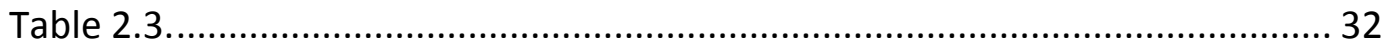

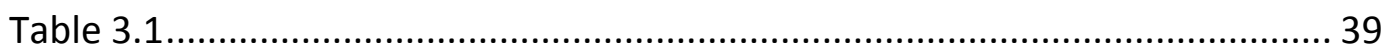

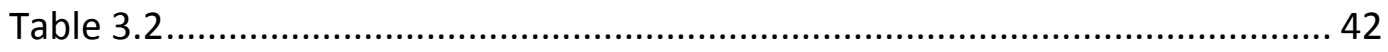




\section{List of Figures}

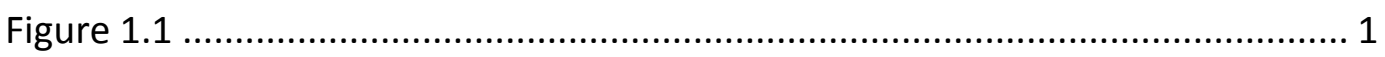

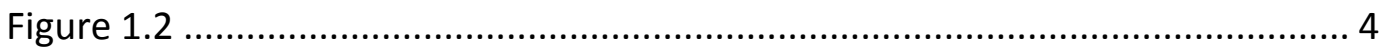

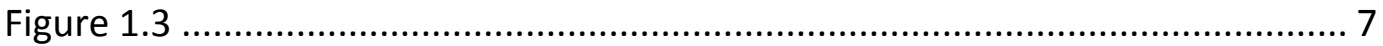

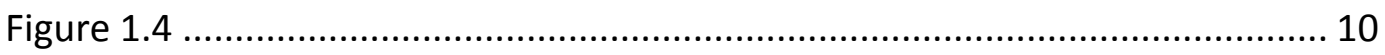

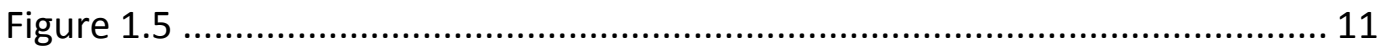

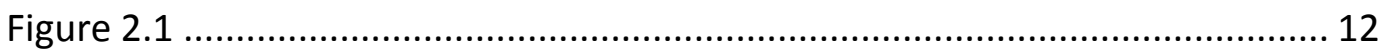

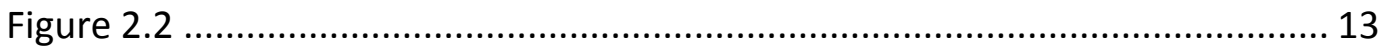

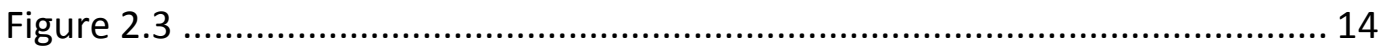

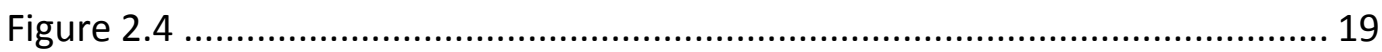

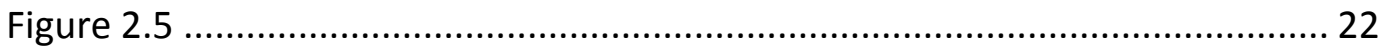

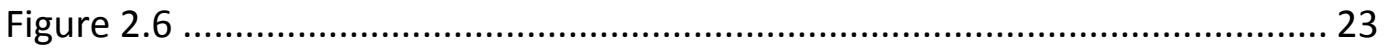

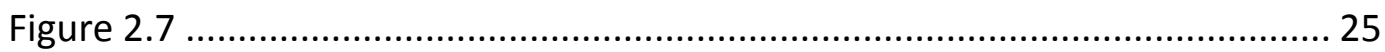

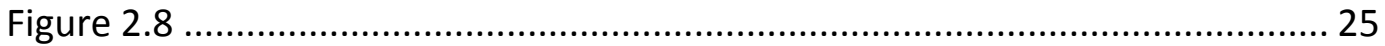



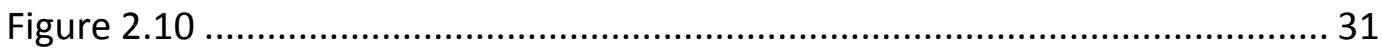

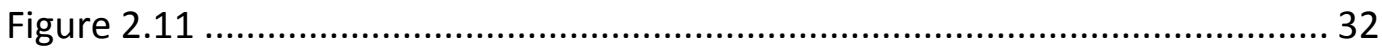

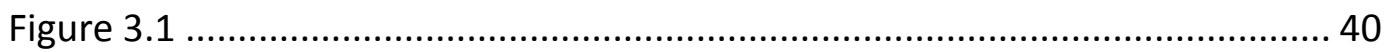

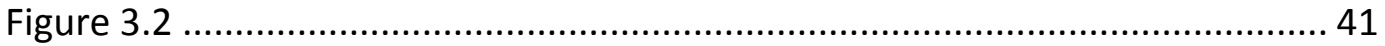

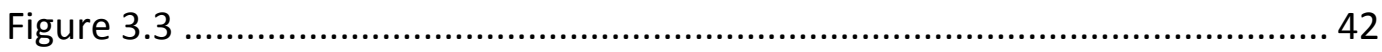

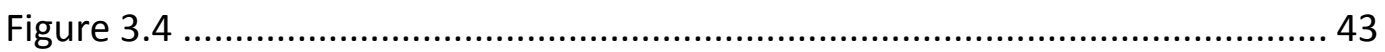

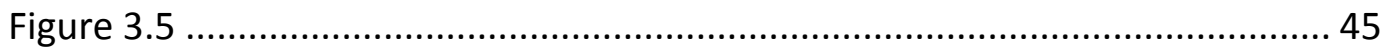

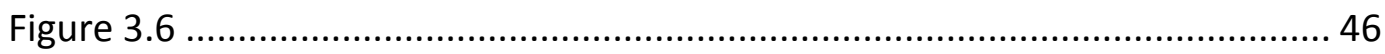

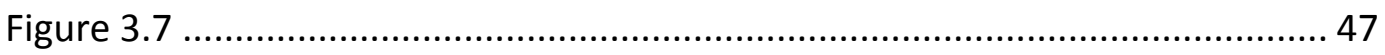

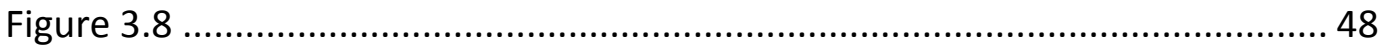

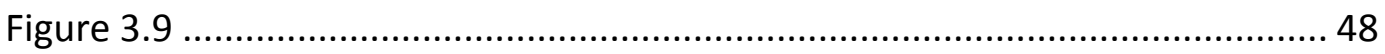

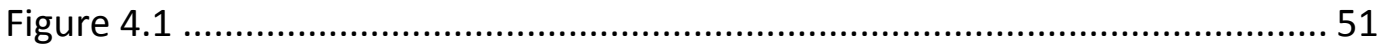




\section{Introduction}

\subsection{Motivation and background}

As the world's second largest energy consumer, the U.S. accounted for roughly $19 \%$ of the world's primary energy consumption in 2010 . Approximately $41 \%$ of the energy consumed in the U.S. in 2010 was consumed by commercial and residential buildings (Figure 1.1)[1]. However, due to diminishing resources, increasing energy costs, and climate change, the United States has seen increased demand for high performance buildings in recent decades. In fact, according to a report by ISBSWorld, the Green and Sustainable Building Construction industry saw revenue increase at an average annual rate of $26.9 \%$ between 2006 and 2011 [2]. Building occupants and owners alike are demanding more comfortable and energy efficient buildings.

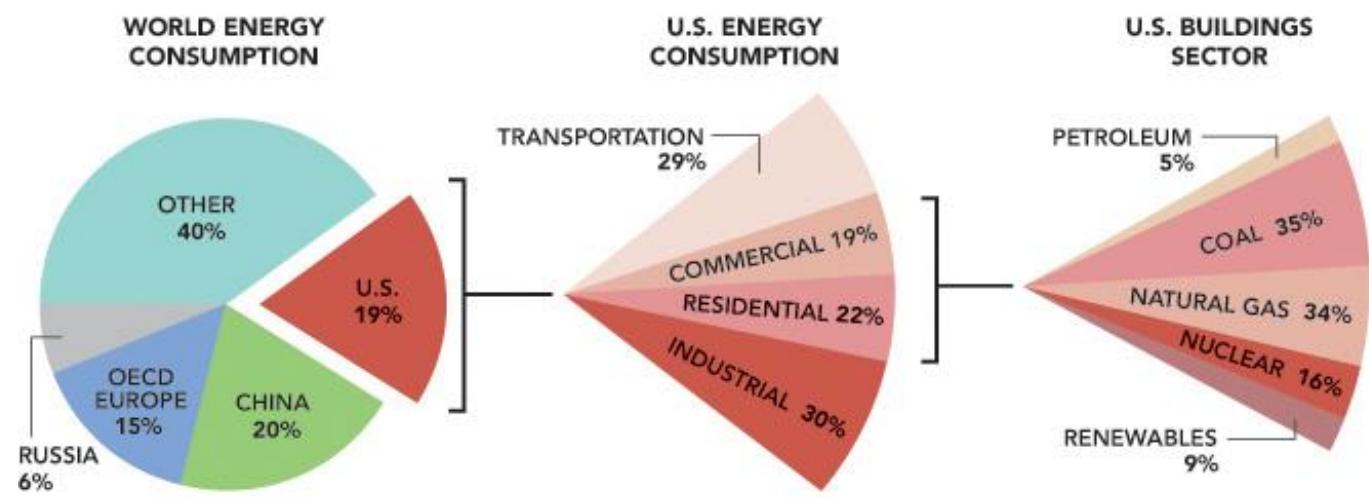

Figure 1.1. An overview of energy consumption in the United States in 2010. Commercial and residential buildings in the U.S. account for $41 \%$ of the country's total source energy consumption. [1].

In response to increased demand, several new building standards and certifications have been created to aid in the design and development of high 
performance buildings. One such standard is Passive House, which originated in Germany and is based on a super-insulated and tightly-sealed building envelope. Although its name implies that the standard is only applicable to residential buildings, the Passive House Standard has been successfully applied to offices, schools, factories, government buildings, and other non-residential structures[3]. However, the standard is predominately used in residential applications. Not to be confused with a passive solar house, the Passive House Standard requires that air infiltration is less than or equal to 0.6 air changes per hour at a 50 Pascal pressure difference, annual heating energy is less than or equal to $15 \mathrm{kWh} / \mathrm{m}^{2}$, and total annual source energy is less than or equal to $120 \mathrm{kWh} / \mathrm{m}^{2}[4]$. The result is a home that is roughly $90 \%$ more energy efficient than a typical home. Passive House design is typically influenced by the use of the Passive House Planning Package (PHPP) spreadsheet program. Treating the building as a single zone, PHPP uses a monthly energy balance to determine heating and cooling loads based on local weather data, internal gains, steady-state R-values, window performance data, and ventilation data[5].

A common complaint of passive house occupants is that, due to the highlyinsulated and air-tight envelope, they tend to overheat during the summer months[6-9]. This results in either increased cooling energy demand or thermal discomfort in cases where no active cooling system is installed. Numerous studies have shown that the addition of thermal mass can reduce temperature fluctuation and shift cooling loads to periods of lower outdoor air 
temperature[10]. This concept could be especially useful in a Passive House, where internal gains have a greater impact on indoor air temperatures.

The use of thermal mass in buildings is certainly not a new concept. In fact, massive wall construction has been used for centuries throughout Europe and the Middle East. But considering that over $90 \%$ of new homes in the United States are framed with wood[11], massive wall construction will likely continue to be a less-common construction method for quite some time. However, thermal mass in the form of Phase Change Materials (PCMs) could potentially meet the need of adding thermal mass to lightweight construction. This could prove to be a valuable energy saving strategy in the United States and abroad.

\subsubsection{Overview of PCM's}

Compared to traditional thermal mass, the use of PCMs in building applications is a relatively new concept that was first introduced in the 1970's $[12,13]$. Like physical mass, PCMs offer the potential to reduce fluctuations in air temperature and shift cooling loads to off-peak periods. In contrast to physical mass, whose energy storage capabilities are restricted to sensible heat, the ability of a PCM to store energy is largely characterized by its latent heat of fusion. As the latent heat of fusion increases, the material's capacity to store heat also increases. When heat is added to a solid below its melt temperature or a liquid above its melt temperature, the energy is stored as sensible heat and increases the temperature of the solid or liquid. However, when heat is added to 
a solid at its melt temperature, the material changes phase to a liquid while maintaining a constant temperature, effectively storing the heat (Figure 1.2). As the liquid freezes and returns to a solid, the stored heat is released to the surrounding environment. This characteristic is especially suited to building applications when the melt temperature of the PCM is approximately equal to the desired room air temperature. Table 1.1 lists the latent heat of fusion and melting point for various materials. Of the materials listed, coconut oil would be potential candidate for building applications due to its melting temperature of $24^{\circ} \mathrm{C}$

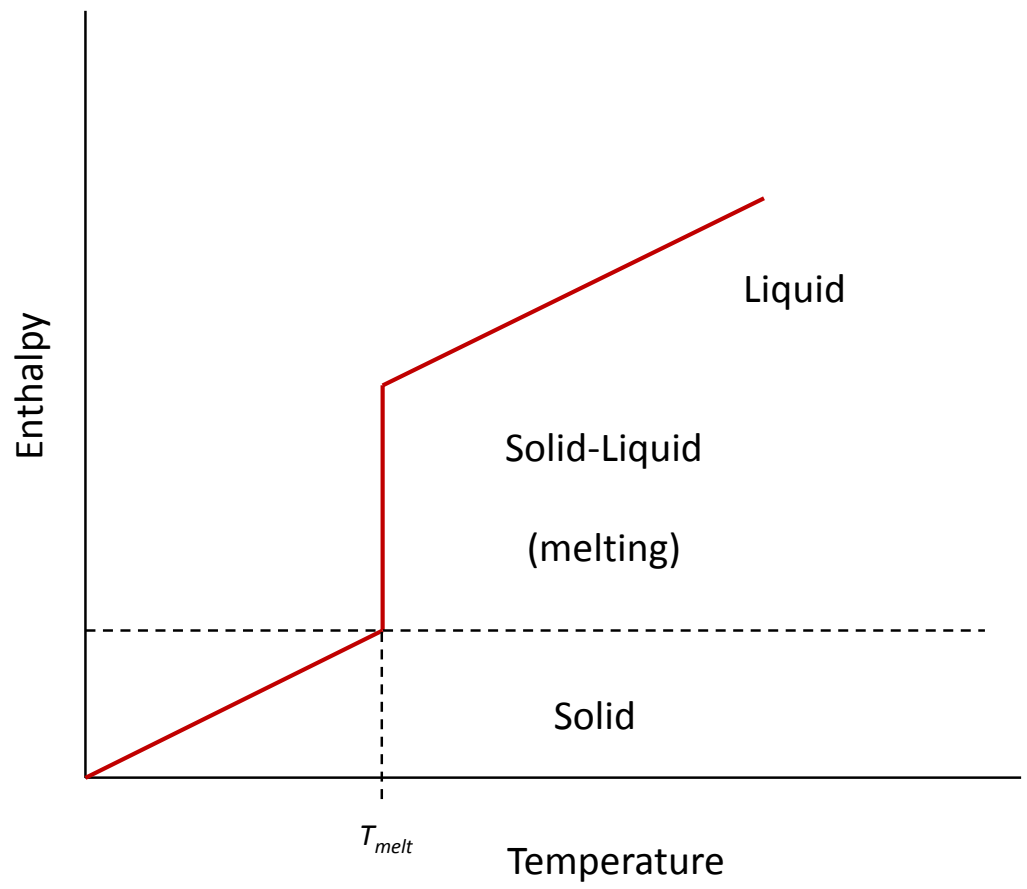

Figure 1.2. Enthalpy curve for an ideal phase change material.

PCMs are broadly categorized into organic compounds, inorganic compounds, and eutectic mixtures[14]. Organic PCMs include paraffins, fatty 
Table 1.1. Latent Heat and Melting Point of various materials.

\begin{tabular}{|l|c|c|}
\hline \multicolumn{1}{|c|}{ Material } & $\begin{array}{c}\text { Latent Heat } \\
\text { of Fusion } \\
(\mathbf{k J} / \mathbf{k g})\end{array}$ & $\begin{array}{c}\text { Melting } \\
\text { Point }\left({ }^{\circ} \mathbf{C}\right)\end{array}$ \\
\hline Lead & 22.4 & 327 \\
\hline Gold & 67 & 1063 \\
\hline Heptane & 140 & -90.5 \\
\hline Coconut Oil & 103 & 24 \\
\hline Paraffin Wax & 147 & 46 \\
\hline Hexane & 152 & -95 \\
\hline Ethylene glycol & 181 & -12.8 \\
\hline Dodecane & 216 & -25.8 \\
\hline Aluminum & 321 & 658 \\
\hline Water & 334 & 0 \\
\hline Ammonia & 339 & -78 \\
\hline
\end{tabular}

acids, and polyethylene glycol and tend to be chemically stable, nonreactive, and resist sub-cooling. However, they also have a relatively low thermal conductivity, low latent heat storage capability, and may be flammable. Inorganic PCMs are typically salt hydrates and possess a high latent heat storage capability,

high thermal conductivity, and are typically non-flammable. However, they are prone to sub-cooling, segregation, and experience high changes in volume during phase transition[15]. Eutectics can be mixtures of only organics, only inorganics, or a combination of the two. They tend to have sharp melting points and latent heat storage capabilities that are slightly above organics, but there is little data available regarding their thermal and physical properties[16]. PCM properties that are desirable for passive building applications include a high thermal conductivity, high latent heat of fusion, non-flammable, and a melting point that is approximately equal to room temperature.

There are generally two ways to contain PCMs in building applications: direct impregnation into building materials and encapsulation. Direct impregnation can be accomplished by either dipping porous building materials into a PCM bath or mixing the PCM into the materials during the manufacturing 
process[14]. Encapsulation involves containing the PCM with another material and can further be categorized into micro- and macro-encapsulation. Microencapsulated PCMs are contained by microscopic polymeric capsules which form a powder-like substance that can be incorporated into various building materials $[14,16]$. Micro-encapsulated PCMs have been successfully incorporated into wallboard, concrete, insulation and acoustic ceiling tiles, but tend to be costly[17-19]. Macro-encapsulation contains the PCM in larger pouches, tubes, or panels that interact with other building materials through conduction and convection. Macro-encapsulated PCMs are typically less costly than their microencapsulated counterparts, but may not release stored heat as effectively due to solidification of the PCM around the edges of the capsule[16]. Examples of micro- and macro-encapsulated PCMs are shown in Figure 1.3.

\subsubsection{PCM applications in buildings}

There are multiple ways to incorporate PCMs into buildings to take advantage of their high thermal storage density. They can be used in both active and passive systems for heating and cooling. In passive applications, PCMs can be incorporated as separate components in the building's construction or integrated directly into building materials. Examples of PCM as a separate component include PCM panels installed below finish flooring and sheets of macro-encapsulated PCM pouches that are installed in a wall behind the gypsum board [20]. Examples of PCM integration into building materials include PCM- 
a)

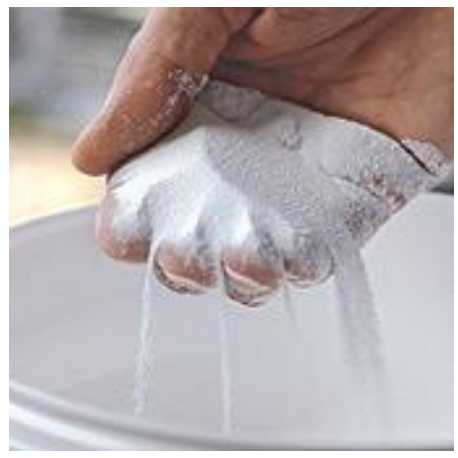

b)

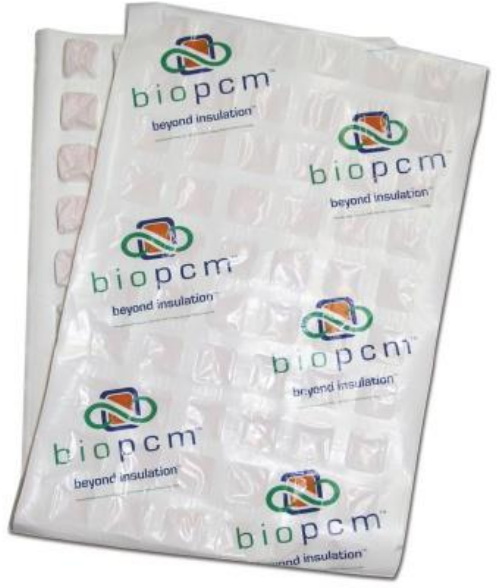

c) ThermalCORE ${ }^{\mathrm{m}}$ Panel

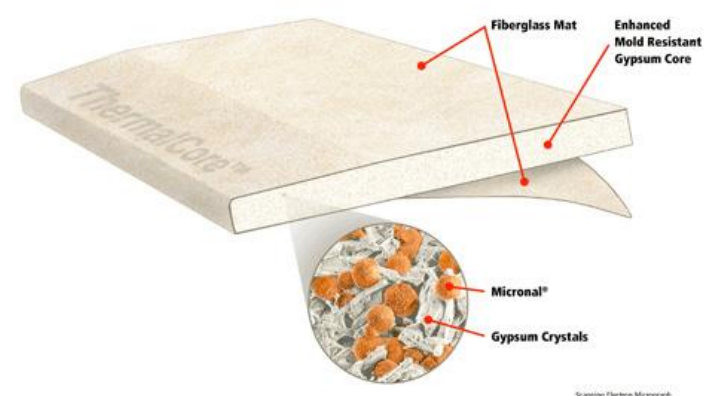

Figure 1.3. a) BASF Micronal ${ }^{\circledR}$ microencapsulated PCM powder (Source: http://www.basf.com), b) Phase Change Energy Solutions macro-encapsulated BioPCmat ${ }^{\mathrm{TM}}$ (Source: http://www.phasechange.com), c) PCM-impregnated ThermalCORE ${ }^{\mathrm{TM}}$ Panel by National Gypsum (Source: http://www. thermalcore.info/).

impregnated wallboard, concrete, ceiling tiles, and insulation. When used in this manner, PCMs will simply store or release energy if the adjacent air or surface temperature is above or below the melting point. Several studies using numeric simulation, experimentation, or both confirm that passive applications of PCMs can help moderate indoor air temperatures that would normally experience greater fluctuation due to direct solar gains, indirect solar gains, and other internal gains $[12,14-16,20]$. The amount of temperature reduction and energy savings varies significantly and is influenced by local climate, internal gains, and other thermal characteristics of the building. 
Considering that PCMs are a form of thermal energy storage, they require some means of dissipating their stored energy when used in passive cooling applications. By dissipating stored heat, the PCMs return to a solid phase and are then ready to begin the melt-freeze cycle again. While a melted PCM would still offer some component of sensible heat storage, not allowing it to completely freeze hinders its ability to perform in a passive cooling application, as latent heat storage is the primary mechanism used to absorb heat throughout the day[21]. In certain climates with large diurnal temperature swings, natural nighttime ventilation can be used to take advantage of free cooling. Otherwise, dissipation of the PCM's stored energy results in additional demand on the mechanical cooling system.

Applications of PCMs in active systems have also been researched extensively $[12,16,20]$. Active systems use fans and pumps to transfer energy to air and water, which serve as the working fluids to move thermal energy. PCMs can be incorporated to store heat from the sun for later use when heating is desired, lessening the demand from active heating coils. Similarly, they can be used to absorb heat that would otherwise increase the load on active cooling coils. Persson and Westermark [22] simulated a PCM "cool storage" device designed to help cool a Passive House in Sweden and found that reductions of $22-36 \%$ of degree hours over $26^{\circ} \mathrm{C}$ were possible with the inclusion of $50-400 \mathrm{~kg}$ of PCM. Zhu et al[12] provide a review of PCM applications in active systems including solar heat pumps, in-floor heating, and a thermally active ceiling panel. 
The authors state that PCM applications in active systems are effective and technically feasible, however the economic feasibility of such applications should be carefully considered prior to their implementation.

Of particular interest in this study is a product called BioPCM, a macroencapsulated PCM made by Phase Change Energy Solutions (Figure 1.3b). BioPCM $^{\mathrm{TM}}$ is available in $0.42-\mathrm{m}$ wide mats that come in lengths of $1.22 \mathrm{~m}$ or 2.44 $\mathrm{m}$. The mats are designed to be fastened to wood or metal studs between the insulation and interior finish layer (e.g. gypsum board) of a wall or ceiling (Figure 1.5). It can also be installed in drop-ceilings by simply laying it across the ceiling tiles. Each mat contains several pouches filled with refined soy and palm kernel oil. It is available in three standard melt temperatures $\left(23^{\circ} \mathrm{C}, 25^{\circ} \mathrm{C}\right.$, and $\left.27^{\circ} \mathrm{C}\right)$, but can also be ordered in custom melt temperatures. It is important to note that, in contrast to an ideal PCM which has an exact melting point, real PCMs melt over a small range of temperatures. Figure 1.5 shows the enthalpy curve for BioPCM25 $5^{\text {m }}$ Standard. It can be seen from this figure that BioPCM25 ${ }^{\text {TM }}$ Standard actually melts between $24^{\circ} \mathrm{C}$ and $26^{\circ} \mathrm{C}$.

This particular product has been used in at least two previous studies. Muruganantham et al[23] evaluated the effect of BioPCM ${ }^{\mathrm{TM}}$ in two identical test sheds in Tempe, Arizona, and observed a maximum peak load shift of 60 minutes and a maximum energy savings of roughly $30 \%$. Campbell and Sailor[24] performed a simulation study that examined the effect of PCM on thermal comfort in 126- $\mathrm{m}^{2}$ Passive Houses located in Phoenix, Arizona, Los Angeles, 
California, Denver, Colorado, and Portland, Oregon. In the Portland, Oregon case, the study found that reductions of $93 \%$ of zone-hours $(\mathrm{ZH})$ and $98 \%$ of zone-degree-hours (ZDH) outside thermal comfort were possible through the addition of $3.1 \mathrm{~kg} / \mathrm{m}^{2}$ floor area of BioPCM ${ }^{\mathrm{TM}}$ with a melt temperature of $25^{\circ} \mathrm{C}$. However, BioPCM ${ }^{\mathrm{TM}}$ was not effective in the Phoenix, Arizona case due to warm nighttime temperatures.

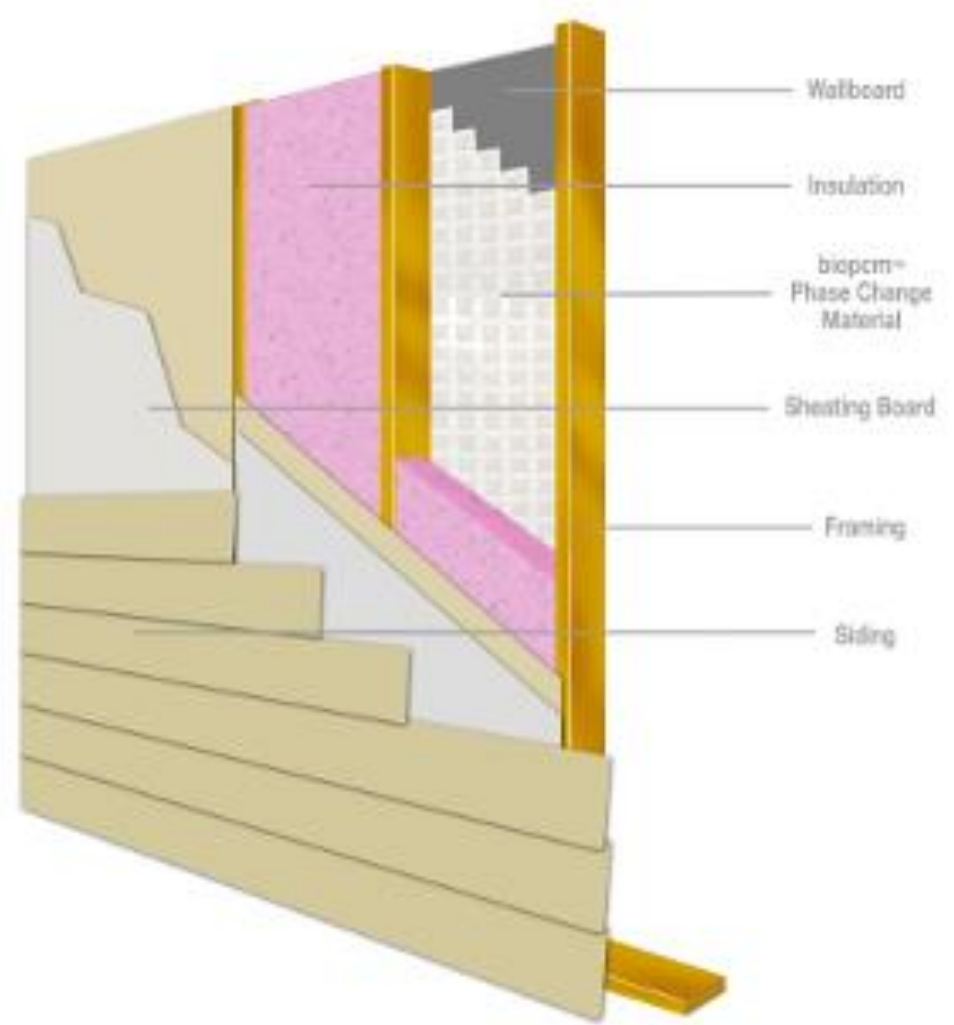

Figure 1.4. BioPCM ${ }^{\mathrm{TM}}$ mats are typically installed between the insulation and finish layer (wallboard) of a wall or ceiling. (Source: http://www.phasechange.com) 


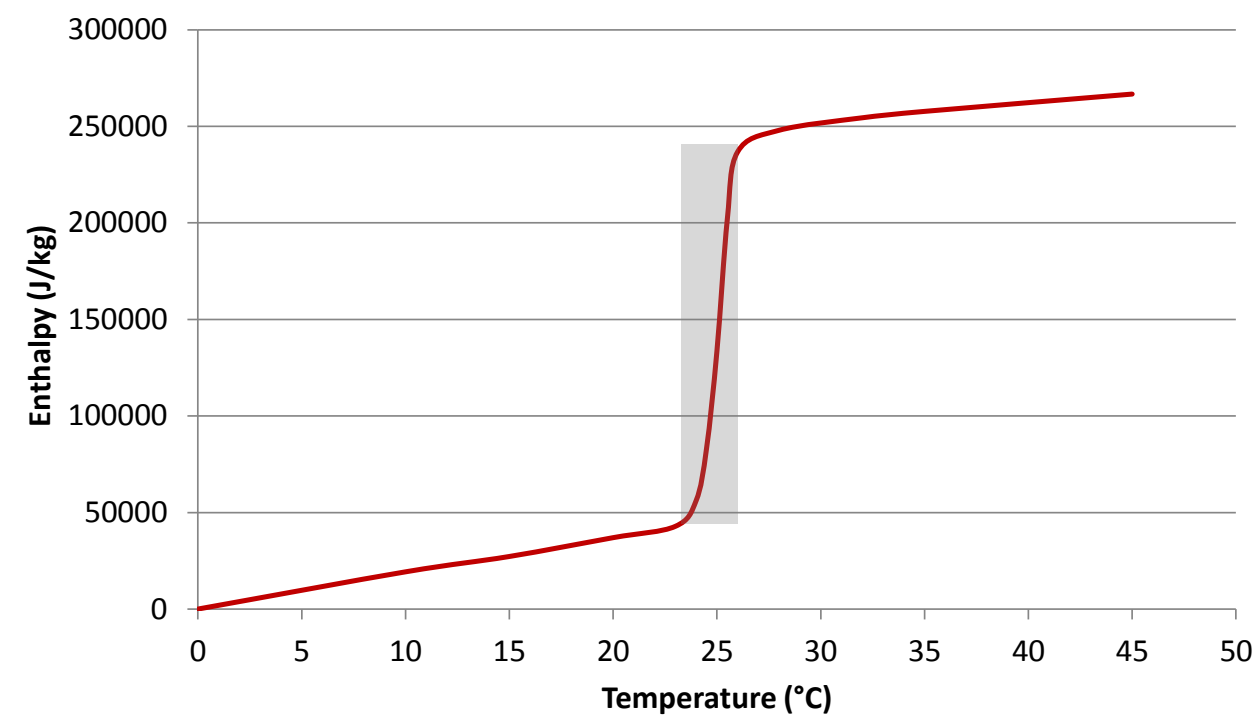

Figure 1.5. Enthalpy curve for BioPCM25 $5^{\mathrm{TM}}$ Standard. Note that the melting temperature ranges from approximately 24 to $26^{\circ} \mathrm{C}$.

\subsection{Purpose of present study}

The present study is a continuation of the prior research performed by Campbell and Sailor[24]. The building simulated in the study was based on an actual Passive House duplex in Portland that was constructed in 2011-2012. Influenced by the results of the Campbell and Sailor study, the actual building includes $130 \mathrm{~kg}\left(0.9 \mathrm{~kg} / \mathrm{m}^{2}\right)$ of BioPCM ${ }^{\mathrm{TM}}$ installed in the second story of the West Unit. The building was thoroughly instrumented throughout the construction phase to monitor various air temperatures, surface temperatures, and submetered electricity consumption. Therefore, the purpose of the present study is to determine the performance of the BioPCM ${ }^{\mathrm{TM}}$ in situ through analysis of measured data and extended simulation. Through such analysis, this study aims to determine the optimum PCM melt temperature and ultimately answer the question, "Can PCM mitigate overheating in a Passive House?" 


\section{Methods}

\subsection{Field Site Description}

\subsubsection{Location and climate}

The test building in the present study, known as "Trekhaus", is a privately-owned, three-bedroom duplex home in Portland, Oregon, constructed to meet the Passive House Standard. Figure 2.1 shows the location of Portland in the western United States. Portland is classified as ASHRAE Climate Zone 4C, a mixed marine climate with 2346 heating degree days and 235 cooling degree

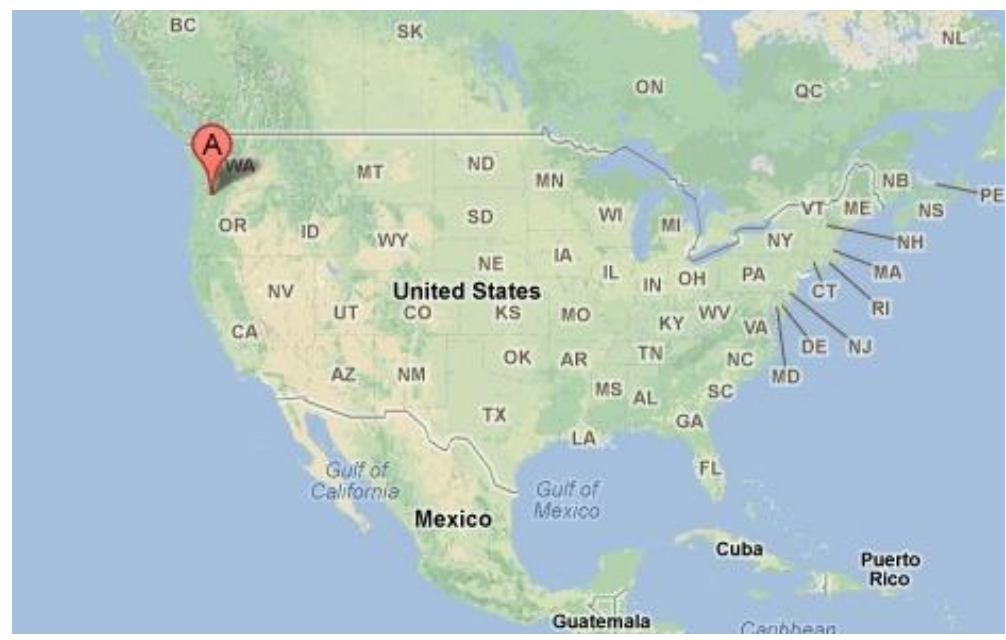

Figure 2.1. The building in this study is located in Portland, OR in the western United States. (Source: http://maps.google.com)

days $\left(18.3^{\circ} \mathrm{C}\right.$ base)[25]. This study is primarily focused on the cooling season, which nominally runs from July 1 through September 30. A typical Portland summer has an average peak temperature of $25.4^{\circ} \mathrm{C}$ and $68.3 \%$ relative humidity. Daytime temperatures can peak to over $37^{\circ} \mathrm{C}$ in the summer; however, nighttime temperatures tend to be $12^{\circ} \mathrm{C}$ cooler on average. This large diurnal 
temperature swing creates an ideal setting to employ passive cooling techniques such as natural ventilation.

\subsubsection{Construction details and occupancy}

Trekhaus is a two-story building that is divided into two mirror-image apartments that share a wall on the north-south axis (Figure 2.2). Each apartment has a total floor area of $145 \mathrm{~m}^{2}$, consisting of three bedrooms, two

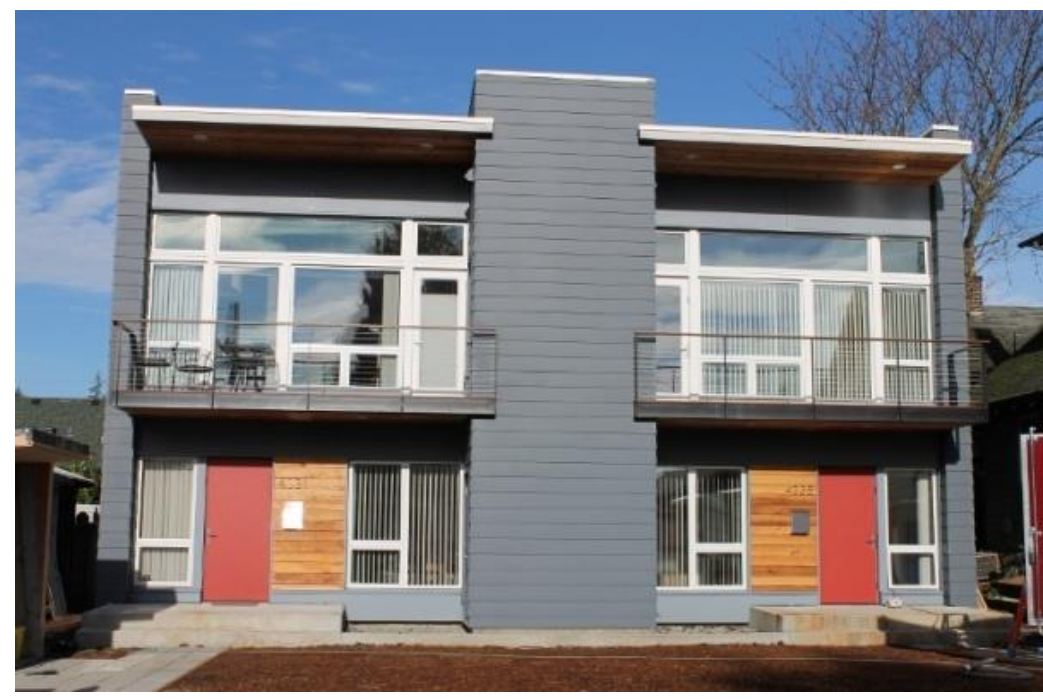

Figure 2.2. Trekhaus, a passive house duplex home, is divided into two mirror-image apartments with a party wall on the north-south axis.

bathrooms, a common living room and kitchen, and an unconditioned workshop with an area of $11.6 \mathrm{~m}^{2}$ (Figure 2.3). A $100 \mathrm{~mm}$ thick concrete slab, fully insulated with $170 \mathrm{~mm}$ of expanded perlite and $100 \mathrm{~mm}$ of expanded polystyrene, serves as the home's foundation. The exterior walls are framed with $38 \times 184 \mathrm{~mm}$ wood studs spaced $0.61 \mathrm{~m}$ on-center. From outside to inside, the layers of the exterior walls include wood siding, $100 \mathrm{~mm}$ foil-faced polyisocyanurate insulation, $12 \mathrm{~mm}$ 
plywood sheathing, $184 \mathrm{~mm}$ blown-in cellulose insulation, and $16 \mathrm{~mm}$ gypsum board. From outside to inside, roof construction consists of a single-ply membrane, $178 \mathrm{~mm}$ polyisocyanurate insulation, $19 \mathrm{~mm}$ plywood decking, 300 $\mathrm{mm}$ blown-in cellulose insulation, and $16 \mathrm{~mm}$ gypsum board. The floor above the unconditioned workshop is constructed of $16 \mathrm{~mm}$ gypsum board, $178 \mathrm{~mm}$
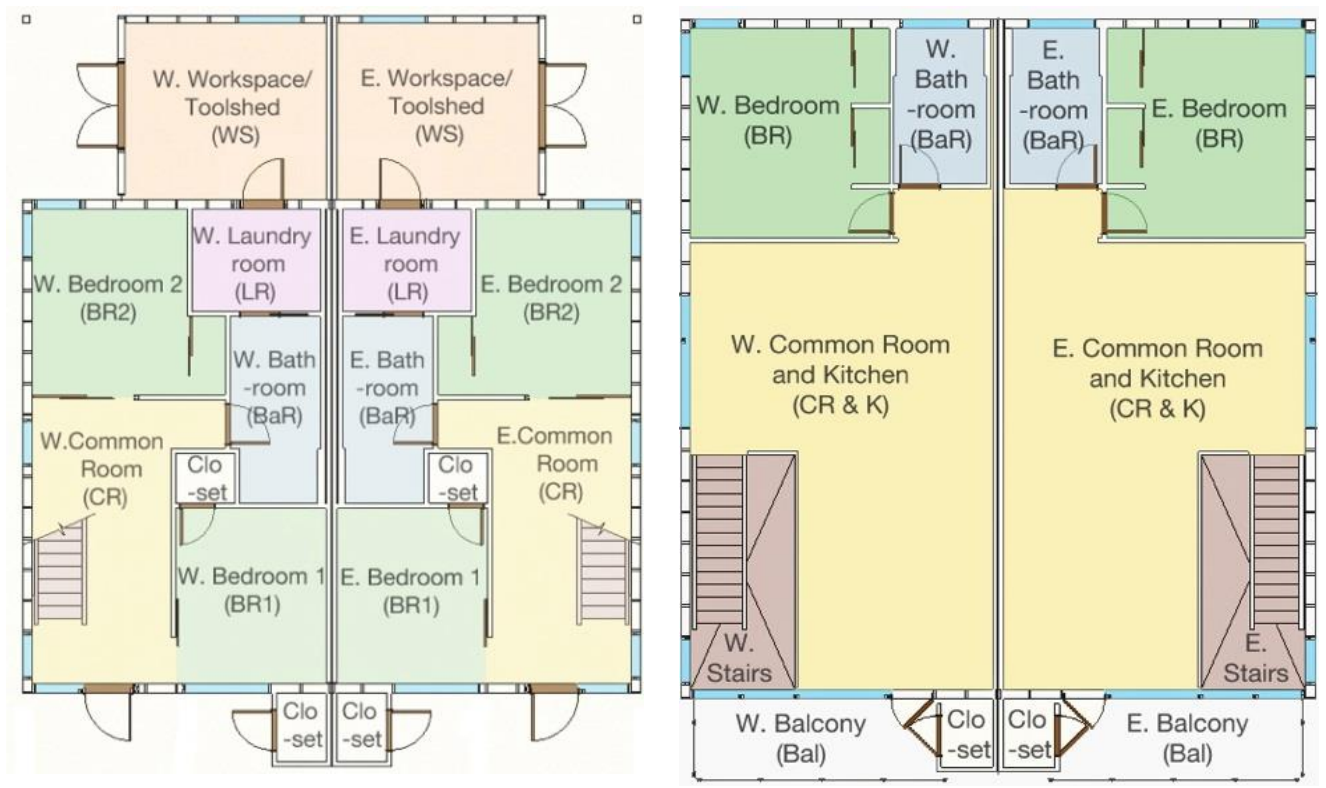

Figure 2.3. Floor plan of the first floor (left) and second floor (right). Note the party wall dividing the east and west apartments.

polyisocyanurate insulation, $300 \mathrm{~mm}$ blown-in cellulose insulation, $19 \mathrm{~mm}$ plywood decking, and finished flooring. The finished flooring is cork in the West Unit and bamboo in the East Unit. Finally, the party wall that separates the East and West Units is constructed of two $38 \times 89 \mathrm{~mm}$ wood-framed walls with an air gap in between. The layers of the wall, from inside the living space to the air gap, include 2 sheets of $16 \mathrm{~mm}$ gypsum board and $89 \mathrm{~mm}$ fiberglass batt insulation. 
Table 2.1 summarizes these constructions and their estimated steady-state R-

values.

Based on the results of Campbell and Sailor [24], BioPCM25 $25^{\mathrm{TM}}$ is installed

in the second story of the West Unit behind the gypsum board in the living room

party wall, living room ceiling, and both sides of the partition wall that separates

the kitchen and bedroom. The East Unit contains no PCM and serves as an

experimental control.

Table 2.1. Typical Trekhaus constructions and their R-values.

\begin{tabular}{|c|c|c|c|c|c|}
\hline Construction & Material & $\begin{array}{c}\text { Thickness } \\
(\mathrm{m})\end{array}$ & $\begin{array}{c}\text { Thermal } \\
\text { Conductivity } \\
(\mathrm{W} / \mathrm{m} \cdot \mathrm{K})\end{array}$ & $\begin{array}{l}\text { R-Value } \\
\left(\mathrm{m}^{2} \cdot \mathrm{k} / \mathrm{W}\right)\end{array}$ & $\begin{array}{c}\text { Total Wall } \\
\text { Assembly R- } \\
\text { Value }\left(\mathrm{m}^{2} \cdot \mathrm{K} / \mathrm{W}\right)\end{array}$ \\
\hline \multirow{3}{*}{$\begin{array}{c}\text { Foundation } \\
\text { Slab }\end{array}$} & Expanded Perlite & 0.171 & 0.054 & 3.156 & \multirow{3}{*}{6.11} \\
\hline & \begin{tabular}{|l|} 
Extruded Polystyrene Insulation \\
\end{tabular} & 0.102 & 0.035 & 2.910 & \\
\hline & Concrete & 0.102 & 2.060 & 0.049 & \\
\hline \multirow{6}{*}{ Exterior Wall } & Siding & 0.019 & 0.103 & 0.185 & \multirow{6}{*}{9.82} \\
\hline & Air Gap & - & - & 0.150 & \\
\hline & \begin{tabular}{|l} 
Polyisocyanurate Insulation \\
\end{tabular} & 0.102 & 0.021 & 4.826 & \\
\hline & Plywood Sheathing & 0.013 & 0.098 & 0.130 & \\
\hline & Blown-in Cellulose Insulation & 0.184 & 0.042 & 4.431 & \\
\hline & Gypsum Board & 0.016 & 0.159 & 0.100 & \\
\hline \multirow{5}{*}{ Roof } & Single-ply Membrane & - & - & - & \multirow{5}{*}{15.97} \\
\hline & Polyisocyanurate Insulation & 0.178 & 0.021 & 8.445 & \\
\hline & \begin{tabular}{|l|} 
Plywood Decking \\
\end{tabular} & 0.016 & 0.098 & 0.162 & \\
\hline & Blown-in Cellulose Insulation & 0.302 & 0.042 & 7.258 & \\
\hline & Gypsum Board & 0.016 & 0.159 & 0.100 & \\
\hline \multirow{5}{*}{$\begin{array}{c}\text { Second Floor } \\
\text { (above } \\
\text { Workshop) }\end{array}$} & Gypsum Board & 0.016 & 0.159 & 0.100 & \multirow{5}{*}{16.07} \\
\hline & Polyisocyanurate Insulation & 0.178 & 0.021 & 8.445 & \\
\hline & Blown-in Cellulose Insulation & 0.302 & 0.042 & 7.258 & \\
\hline & Plywood Decking & 0.019 & 0.098 & 0.194 & \\
\hline & Finish Flooring & 0.013 & 0.166 & 0.077 & \\
\hline \multirow{5}{*}{$\begin{array}{c}\text { Exterior } \\
\text { Workshop Wall }\end{array}$} & Siding & 0.019 & 0.103 & 0.185 & \multirow{5}{*}{2.60} \\
\hline & \begin{tabular}{|l|} 
Air Gap \\
\end{tabular} & - & - & 0.150 & \\
\hline & \begin{tabular}{|l|} 
Plywood Sheathing \\
\end{tabular} & 0.013 & 0.098 & 0.130 & \\
\hline & Fiberglass Batt Insulation & 0.089 & 0.043 & 2.055 & \\
\hline & Gypsum Board & 0.013 & 0.159 & 0.080 & \\
\hline \multirow{7}{*}{ Party Wall } & Gypsum Board & 0.016 & 0.159 & 0.100 & \multirow{7}{*}{4.69} \\
\hline & Gypsum Board & 0.016 & 0.159 & 0.100 & \\
\hline & Fiberglass Batt Insulation & 0.089 & 0.043 & 2.055 & \\
\hline & Air Gap & - & - & 0.180 & \\
\hline & Fiberglass Batt Insulation & 0.089 & 0.043 & 2.055 & \\
\hline & Gypsum Board & 0.016 & 0.159 & 0.100 & \\
\hline & Gypsum Board & 0.016 & 0.159 & 0.100 & \\
\hline
\end{tabular}


High performance windows are often used in Passive Houses to help meet the standard's stringent heating energy requirements. The windows used in Trekhaus are no exception and feature three layers of glazing with a $90 \%$ argon/10\% air mixture in between the layers. Low-emissivity coatings are also incorporated to further enhance window performance. The location of the coatings will affect the window system's center-of-glass U-factor and Solar Heat Gain Coefficient (SHGC). The windows used on the south façade have lowemissivity coatings on surfaces three and five while the remaining windows have low-emissivity coatings on surfaces two and five. Table 2.2 provides a summary of window performance characteristics.

Table 2.2. Performance characteristics of the windows used in Trekhaus.

\begin{tabular}{|c|c|c|c|c|c|c|c|}
\hline \multirow[b]{2}{*}{ Façade } & \multirow[b]{2}{*}{$\begin{array}{c}\text { Window } \\
\text { Type }\end{array}$} & \multirow[b]{2}{*}{\begin{tabular}{|c} 
Low-e \\
Surfaces
\end{tabular}} & \multicolumn{3}{|c|}{ Center of Glass } & \multicolumn{2}{|c|}{ Total Window } \\
\hline & & & \begin{tabular}{|c|} 
Visible \\
Transmittance
\end{tabular} & SHGC & $\begin{array}{l}\text { U-factor } \\
\left(\mathrm{W} / \mathrm{m}^{2 \cdot} \mathrm{K}\right)\end{array}$ & SHGC & $\begin{array}{l}\text { U-factor } \\
\left(\mathrm{W} / \mathrm{m}^{2 \cdot} \mathrm{K}\right)\end{array}$ \\
\hline \multirow[b]{2}{*}{ South } & Fixed & 3,5 & 0.63 & 0.59 & 0.88 & 0.51 & 0.97 \\
\hline & Operable & 3,5 & 0.63 & 0.61 & 0.90 & 0.42 & 1.11 \\
\hline \multirow[b]{2}{*}{ North, East, West } & Fixed & 2,5 & 0.57 & 0.36 & 0.71 & 0.31 & 0.81 \\
\hline & Operable & 2,5 & 0.57 & 0.37 & 0.71 & 0.25 & 0.98 \\
\hline
\end{tabular}

In order to meet the low annual primary energy requirement of the Passive House standard, it is often necessary to use energy efficient appliances and non-conventional equipment for heating, cooling, and ventilation. To this end, Trekhaus heating and cooling is provided by a Mitsubishi Mr. Slim mini-split heat pump, consisting of an SUZ-KA09NA outdoor unit coupled to an SEZKD09NA indoor unit. This system has rated heating and cooling capacities of 3.2 $\mathrm{kW}$ and $2.4 \mathrm{~kW}$, respectively, and provides conditioned air to the upstairs and 
downstairs common areas. Additional heating in each of the bathrooms is provided via $750 \mathrm{~W}$, fan-forced, electric wall heaters.

Due to the extremely low natural infiltration rate of a Passive House, a dedicated mechanical ventilation system is needed to maintain indoor air quality. However, simply exchanging conditioned room air for unconditioned outdoor air would substantially increase heating and cooling loads. Heat recovery can significantly reduce these loads by using the exhausted room air to warm or cool incoming outdoor air via a flat plate heat exchanger. This system is known as a Heat Recovery Ventilator (HRV). The model used in Trekhaus is a Zehnder ComfoAir ${ }^{\mathrm{TM}} 350$ and is rated to provide a maximum ventilation rate of $350 \mathrm{~m}^{3} / \mathrm{h}$. It is important to note that while some heat recovery systems, known as Enthalpy Recovery Ventilators (ERV), can deal with both sensible and latent heat, this particular model only deals with sensible heat.

Domestic water heating is provided by an AirGenerate AirTap ${ }^{\text {TM }}$ ATI50 heat pump water heater (HPWH) with a storage capacity of $189 \mathrm{~L}$. The compressor and evaporator are fixed to the tank so, when the unit is operating in heat pump mode, any heat that is added to the water is removed from the air in the unconditioned workshop where the unit is located. The unit can be operated with the heat pump only, heat pump and backup electric element, and electric element only. The heat pump is rated at $2.75 \mathrm{~kW}$ while the primary and backup electric elements are each rated at $4 \mathrm{~kW}$.

Construction of the West Unit was completed in December 2011. At that 
time, the unit was occupied by two adults, the owners of the property. East Unit construction was completed in April 2012 and the unit was occupied by one adult at that time. An additional adult occupant was added to the East Unit at the end of August 2012.

\subsubsection{Instrumentation and data collection}

Access to the site throughout the construction phase allowed for an extensive instrumentation and data collection plan. Various surface and air temperatures were measured using Type-T thermocouples. Using empty smoke detector housings to disguise and protect the thermocouples, air temperatures were monitored in both of the first floor bedrooms, the first floor common room, and second floor bedroom. Monitored surface temperatures include two locations on the second story common room floor, one location on the partition wall between the kitchen and bedroom, and three locations along the party wall. A Siemens QPA-2062 three-in-one sensor was installed in the second story common room to monitor air temperature, relative humidity, and carbon dioxide concentration. Thermocouples were also embedded in four different locations at the base of the foundation slab as well as on the surface of the slab. Finally, thermocouples were embedded in four of the PCM pouches in the West Unit: three along the party wall and one on the partition wall between the kitchen and bedroom. A summary of sensor placement is shown in Figure 2.4. Note that Positions 1-4 indicate the location of the surface temperature sensors and PCM 
temperature sensors.

In addition to air and surface temperatures, the data collection plan also included other temperature and flow measurements for specific equipment. HRV measurements including temperatures of incoming outdoor air, supply room air, return room air, and exhaust air. Water heater measurements include hot water
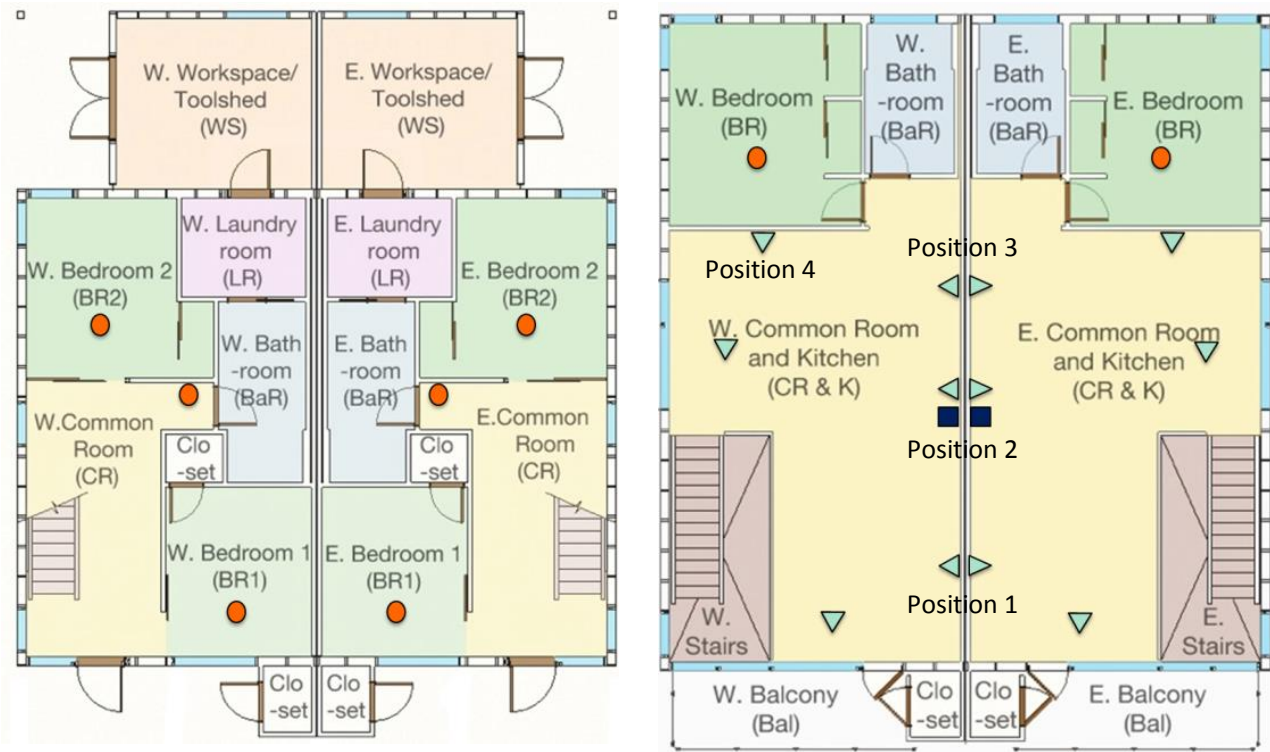

Air Temperature

$\nabla$ Surface Temperature

Siemens QPA-2062 (T/RH/CO2)

Figure 2.4. Locations of various sensors on the first (left) and second (right) floors of the Trekhaus. Note that the Siemens sensor includes temperature, relative humidity, and $\mathrm{CO} 2$ concentration.

flow rate and temperatures of the water entering and leaving the HPHW.

Window and door switches were used to measure how often windows and doors were open. Electricity consumption was also monitored by sub-metering the service panel. Current transducers were installed on individual circuits or groups of circuits and connected to WattNode ${ }^{\circledR} \mathrm{kWh}$ meters.

For the above sensors, data acquisition was accomplished through a Campbell Scientific ${ }^{\circledR}$ CR1000 data logger and two AM25T 25-channel 
multiplexers. Data were sampled every five seconds and averaged every 15 minutes. It is important to note that each apartment had its own data acquisition equipment.

An Onset ${ }^{\circledR}$ weather station was installed on the roof of the building to collect ambient dry-bulb air temperature, relative humidity, wind speed and direction, and global horizontal solar radiation. Weather data were sampled every five minutes and averaged hourly.

Time lapse cameras were deployed to collect data on interior window blind usage. The cameras were temporarily placed inside each apartment and pointed south at the windows in the second floor common room. A photo was taken once per hour, 24 hours per day for a period of about six months. The pictures were then analyzed to determine an approximate schedule of blind usage in each apartment.

Finally, occupants were surveyed to better understand occupant schedules, energy use habits, and occupants' perceptions of the living space.

\subsection{EnergyPlus Model Description}

\subsubsection{Model history and overview}

The energy model used in this study was created using EnergyPlus, a whole building energy simulation code developed by the U.S. Department of Energy. While EnergyPlus is a very powerful simulation code, it does not include a user-friendly graphical user interface (GUI) and is often used with third-party 
GUI's to allow for easier model construction. The preliminary energy model used in this study was first created by Christophe Parroco (a former staff member of the Green Building Research Laboratory) using the third-party GUI, DesignBuilder ${ }^{\mathrm{TM}}$, and then exported to the EnergyPlus Input Data File format. Further development of the HVAC systems, mainly the mini-split heat pump and HRV, was performed by Daeho Kang (a postdoctoral researcher in the Green Building Research Laboratory). At this point, the model was working but used weekly estimated schedules for internal gains and lighting. In addition, it had yet to be validated using observed data from the actual building.

For simulation purposes, the model is divided into seven zones per apartment for a total of 14 zones. In each apartment, the second floor zones include the bathroom, bedroom, and a common room for the kitchen and living room. The first floor zones include the north bedroom, bathroom (which also includes the laundry room), a common room that includes the foyer and south bedroom, and the unconditioned workshop. Figure 2.5 shows a diagram of the model zones.

\subsubsection{Validation}

In order to validate the building energy model, a custom weather file was created using data from the roof-top weather station. Diffuse horizontal solar radiation was required by EnergyPlus, but not measured directly by the weather station. This radiation flux term was therefore estimated using the method 



Figure 2.5. Zoning used in the EnergyPlus model of Trekhaus. Note that the thick black lines indicate zone boundaries. There are a total of seven zones in each unit, four on the first floor (left) and three on the second floor (right).

outlined by Erbs et al[26]. This method uses the clearness index, $k_{t}$, which compares the global horizontal solar radiation measured at the site to the radiation available based on extraterrestrial radiation and solar altitude. Data for extraterrestrial solar irradiance, $I_{o}$, were obtained using the National Renewable Energy Laboratory's solar position calculator, SOLPOS. Equations 1-5 summarize the calculations used in this method, where $k_{t}$ is the clearness index (dimensionless), $k_{d}$ is the diffuse fraction (dimensionless), $I$ is the global horizontal solar radiation $\left(\mathrm{W} / \mathrm{m}^{2}\right), I_{d}$ is the diffuse horizontal solar radiation $\left(\mathrm{W} / \mathrm{m}^{2}\right), I_{o}$ is the extraterrestrial solar radiation $\left(\mathrm{W} / \mathrm{m}^{2}\right)$, and $\alpha$ is the solar altitude (degrees). 


$$
\begin{gathered}
k_{t}=\frac{I}{I_{o} \cdot \sin \alpha} \\
k_{d}=\frac{I_{d}}{I}
\end{gathered}
$$

Interval $k_{t} \leq 0.22$ :

$$
k_{d}=1-0.09 k_{t}
$$

$$
\begin{array}{cc}
0.22 \leq k_{t} \leq 0.8: & k_{d}=0.9511-0.1604 k_{t}+4.39 k_{t}^{2}-16.64 k_{t}^{3}+12.34 k_{t}^{4} \\
k_{t}>0.8: & k_{d}=0.165
\end{array}
$$

To illustrate the importance of careful model validation in EnergyPlus Figure 2.6 compares observed air temperature data of the second floor West Unit Common Room to that predicted by the simulated building prior to validation and model refinement. The root-mean-square error (RMSE) of the hourly average zone temperature in this initial comparison was $10.5^{\circ} \mathrm{C}$. It is

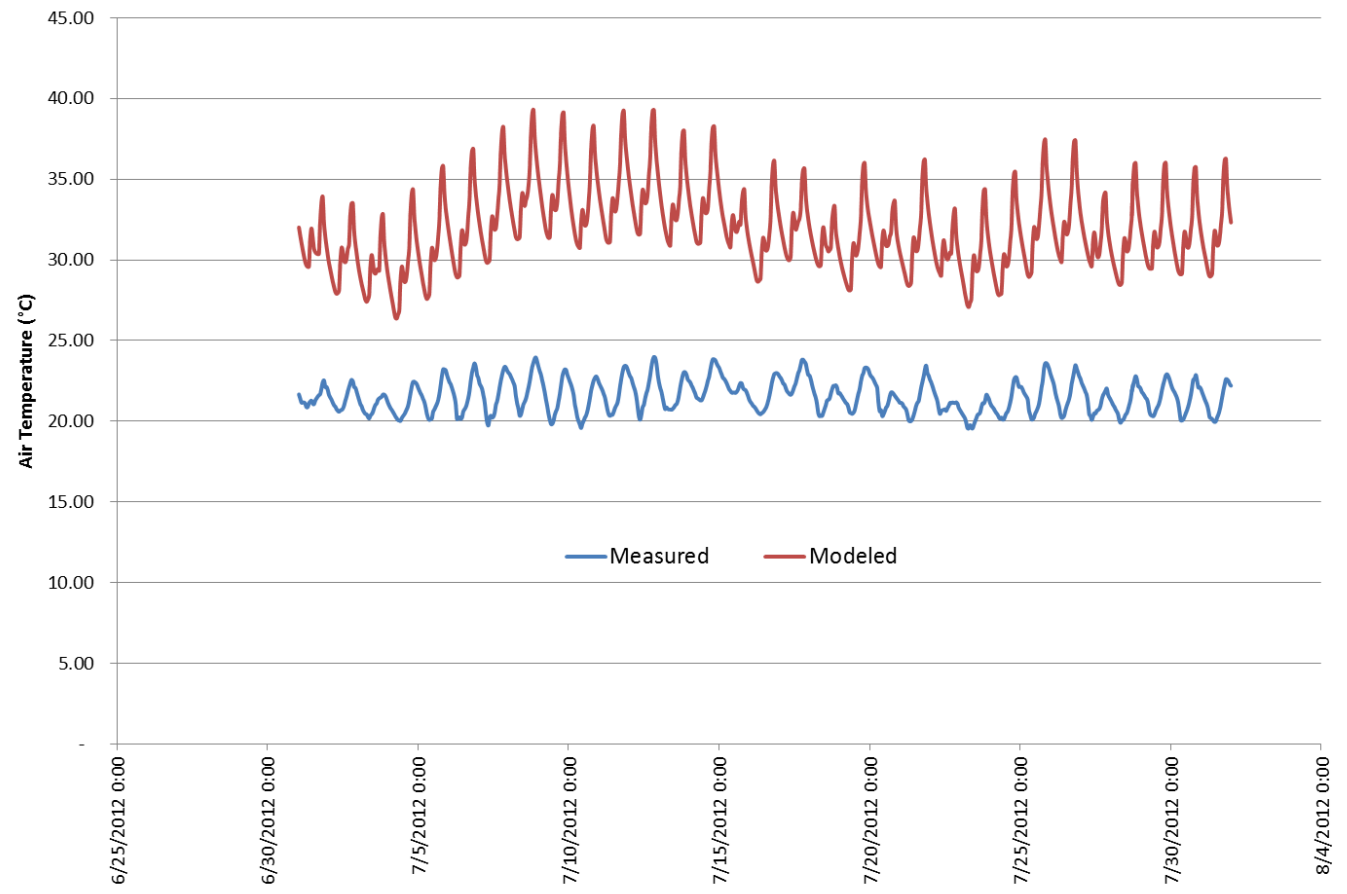

Figure 2.6. Initial comparison of the measured and modeled West Unit second floor common room air temperature. The measured temperature is much lower than that predicted by the preliminary EnergyPlus model. 
obvious that observed temperatures are much lower than those projected by the model, indicating that significant model refinement is needed.

After comparing observed temperatures from the various sensors, a bias in the temperature readings from the Siemens QPA-2062 three-in-one sensor was suspected. Additionally, during an independent test in the West Unit's second floor living room, two Onset $\mathrm{HOBO}^{\circledR} \mathrm{U} 12$ temperature and relative humidity data loggers were deployed for a period of roughly three weeks. Both $\mathrm{HOBO}^{\circledR}$ loggers measured similar temperatures that were approximately two to three degrees Celsius higher than temperatures measured by the Siemens QPA2062 during the same period (Figure 2.7). This bias also agrees with a candid comment from one of the West Unit occupants, who observed readings of approximately $80^{\circ} \mathrm{F}$ on the mini-split heat pump controller display and on an inexpensive digital thermometer during a particular warm period in July. During this same period the highest temperature recorded from the Siemens sensor was approximately $75.2^{\circ} \mathrm{F}$. Therefore, the data from the $\mathrm{HOBO}^{\circledR}$ loggers for the brief calibration period was used to create a correction factor for the Siemens sensor temperature data. The average of the $\mathrm{HOBO}^{\circledR}$ logger temperatures was plotted against the Siemens sensor $\mathrm{mV}$ output and a linear regression curve-fit was used to determine the correction equation (Figure 2.8). It can be seen that the bias of the Siemens sensor is approximately $2.8^{\circ} \mathrm{C}$. 


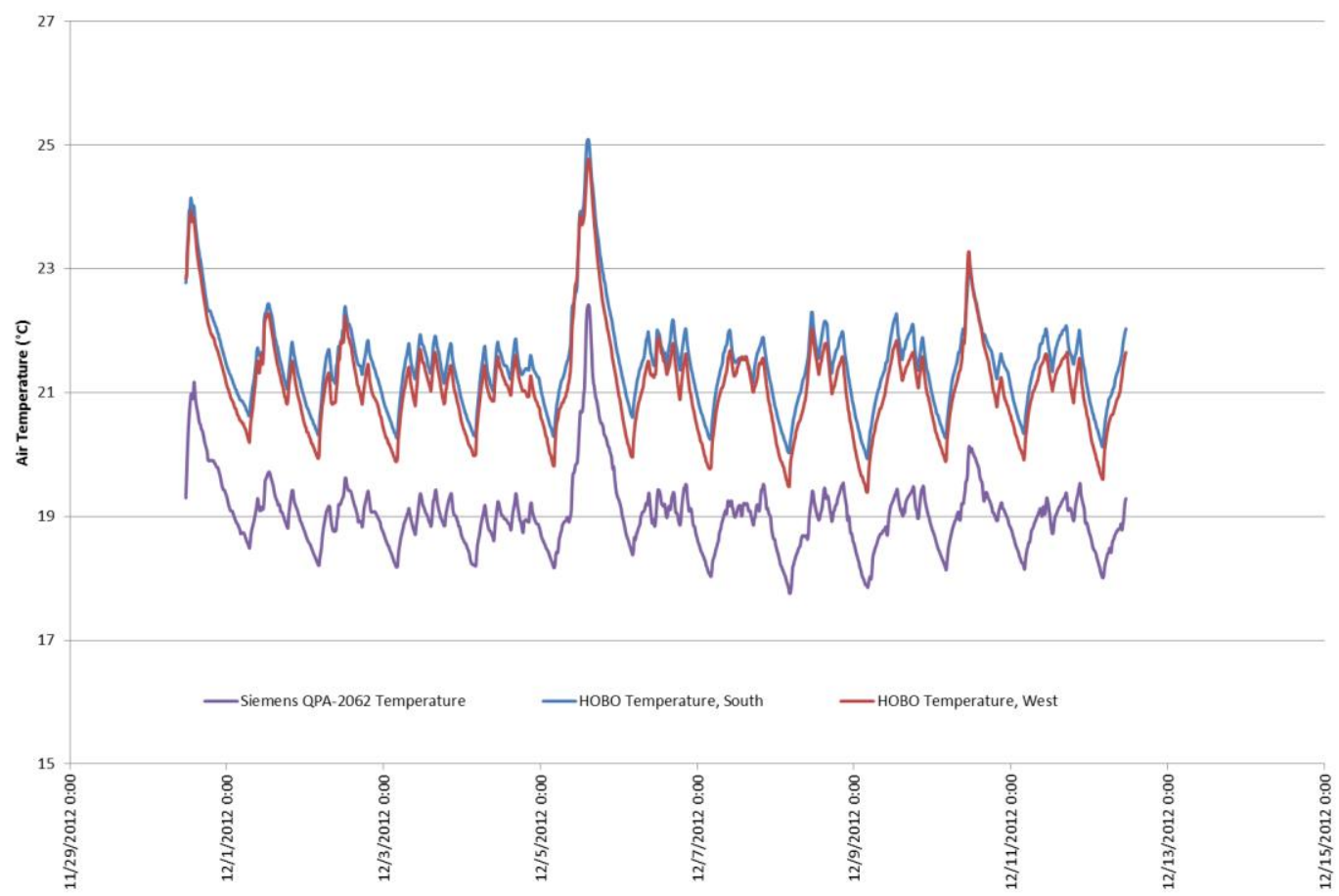

Figure 2.7. Air temperature as measured by the Siemens QPA-2062 sensor and two $\mathrm{HOBO}^{\mathrm{TM}}$ U12 data loggers. The Siemens measurement is consistently lower than both $\mathrm{HOBO}^{\mathrm{TM}}$ loggers.

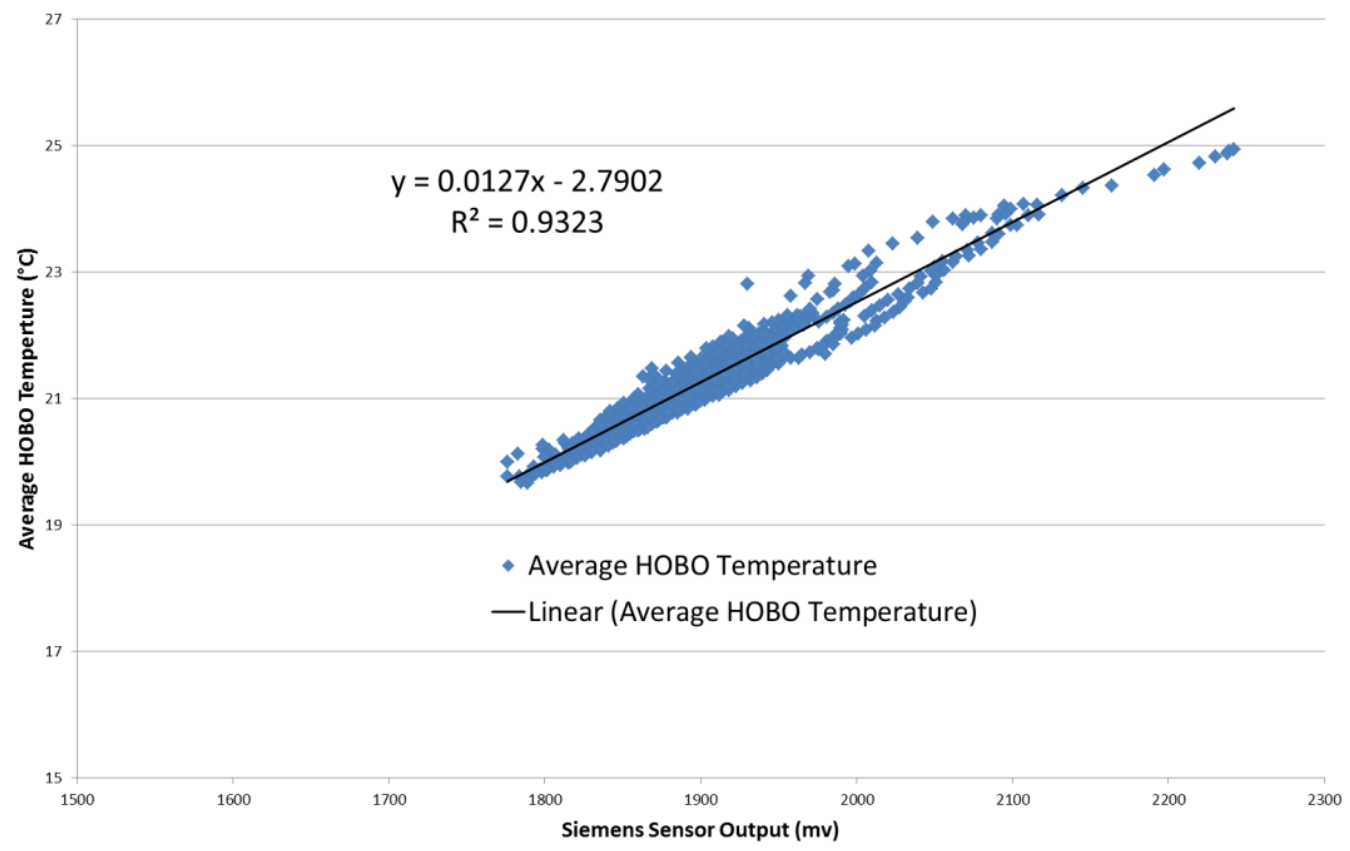

Figure 2.8. Data from the two $\mathrm{HOBO}^{\mathrm{TM}}$ data loggers was used to determine new calibration constants for the Siemens sensor temperature measurement. 
Using the calculated calibration constant, the RMSE for hourly average zone temperature was reduced to $7.6^{\circ} \mathrm{C}$ (Figure 2.9). Therefore, it was still necessary to make several changes to the model to more-accurately predict zone temperatures. Major changes were made to the windows, schedules, zone mixing, natural ventilation, and HVAC systems.

The preliminary model neglected the area of window frames and dividers and used the area of the rough opening indicated in the PHPP spreadsheet. As a

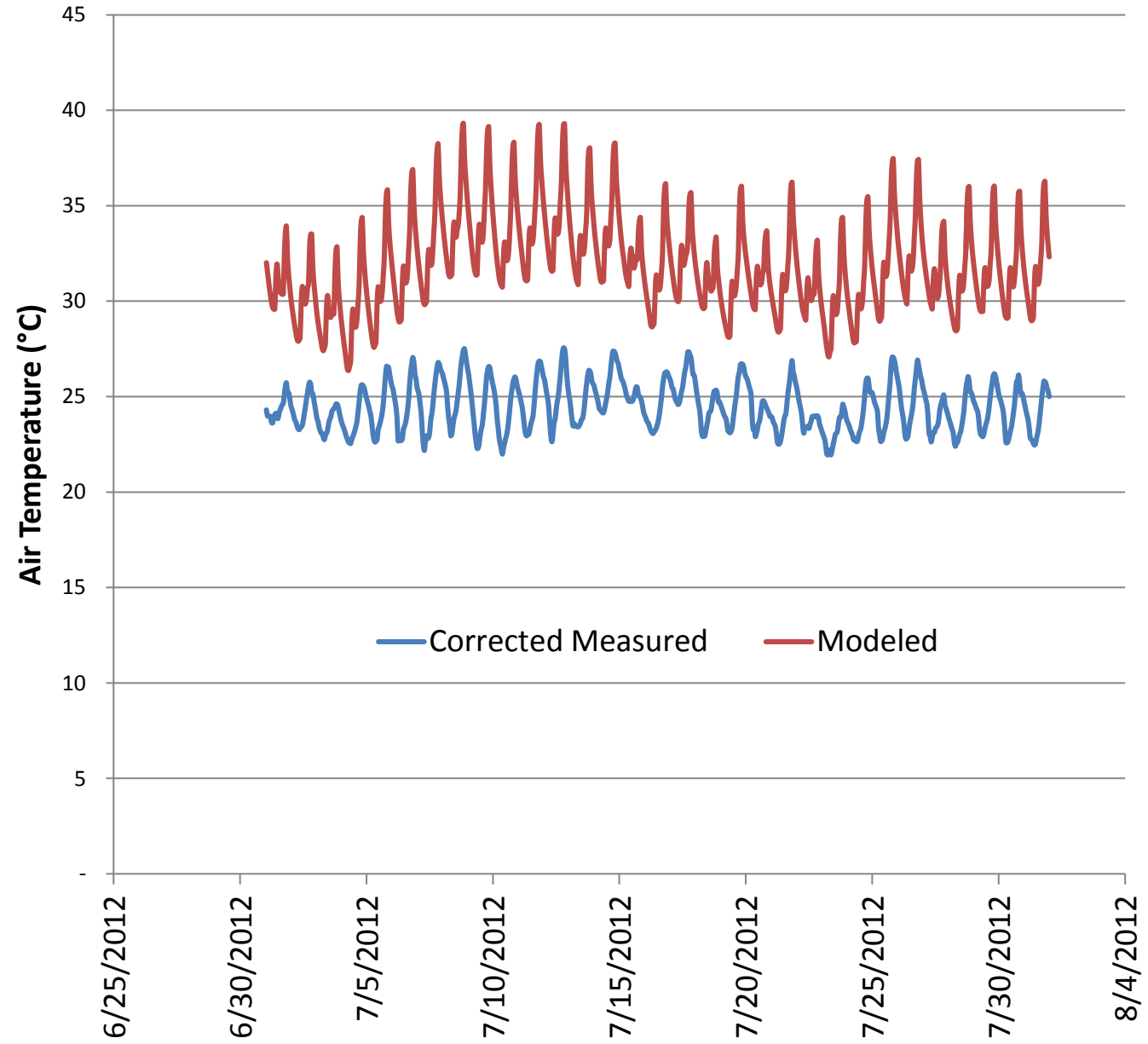

Figure 2.9. Comparison of the modeled air temperature in the West Unit second floor common room compared the measured using the calculated calibration constant. The measured temperature is still much lower than that projected by the preliminary EnergyPlus model. 
result, the glazing area was overestimated by $18-38 \%$, depending on the façade. In addition, the original model used EnergyPlus' WindowMaterial:SimpleGlazingSystem object. This object simply requires the user to input the center-of-glass U-factor and SHGC. EnergyPlus then expands these simple performance indices into a model of a complete glazing system[27]. While convenient, the preferred method is to construct the window layer by layer using the actual window's glazing properties. Therefore, the windows in the model were specified using this layer-by-layer method and the net glazing area was reduced to match that in the PHPP spreadsheet. Window frames and dividers were also added, as well as a $114.3 \mathrm{~mm}$ reveal.

In order to accurately model the consumption of resources and their effect on indoor air temperatures, hourly schedule files for lighting, plug loads, hot water consumption, and cold water supply temperatures were created from observed data. In addition, an hourly fraction schedule for window operation was created from observed data. Finally, an hourly schedule for window blind usage was created using the images captured by the time lapse cameras.

Zone mixing is modeled using the simplified ZoneMixing object. This object only affects the receiving zone and does not have an effect on the source zone[27]. In order to simulate cross mixing of zones using this object, one must have complimentary mixing statements for the source and receiving zones. It was noted that the original model did not include complimentary mixing statements, so they were added to simulate cross mixing of the zones. In 
addition, statements were added to simulate mixing between the workshop and the first floor bathroom. Workshop-bathroom mixing is modified by an hourly fraction schedule based on observed data of when the door connecting the two spaces is open.

Natural Ventilation is modeled using the simplified ZoneVentilation:DesignFlowRate object. This statement allows the user to input a design flow rate that is modified by a fraction schedule and user-selected coefficients. For a given timestep, the ventilation rate is calculated using Equation 6 , where $A, B, C$, and $D$ are user-selected coefficients and $F_{\text {schedule }}$ is a fraction between 0 and 1 based on a user-specified ventilation schedule.

$$
\begin{gathered}
V_{\text {Timestep }}=V_{\text {design }} \cdot F_{\text {schedule }}\left[A+B\left|T_{\text {zone }}+T_{\text {odb }}\right|+C(\text { WindSpeed })\right. \\
\left.+D(\text { WindSpeed })^{2}\right]
\end{gathered}
$$

Ventilation can be further controlled by specifying indoor temperature limits, outdoor temperature limits, or an indoor-outdoor temperature delta. The ventilaltion rate will automatically be set to zero when the specified conditions are not met. The preliminary model included ventilation statements for only the common rooms and assumed that a maximum ventilation rate of $0.5 \mathrm{ACH}$ would occur if the indoor temperature was between 15 and $24^{\circ} \mathrm{C}$ and the outdoor temperature was between 10 and $26^{\circ} \mathrm{C}$. This assumption was further modified by the ventilation schedule, which limited ventilation to two hours in the morning and two hours in the evening and reduced the ventilation rate $25 \%$ to $75 \%$. The refined model uses an hourly fraction schedule based on data 
measured with the installed window switches to modify the design flow rate. In addition, maximum temperature limiting controls were removed and minimum indoor and outdoor air temperature limits were set to $22^{\circ} \mathrm{C}$ and $12^{\circ} \mathrm{C}$, respectively. Figure 2.10 shows EnergyPlus screenshots of the ventilation assumptions in the preliminary and refined models.

Changes to the HVAC systems include the addition of a heat pump water heater in the unconditioned workshop and modifications to the heat recovery ventilator. The preliminary model made use of the WaterUse:Equipment object to estimate the energy needed to heat water for domestic purposes. While this object simulates both hot and cold water end uses, it does not simulate the air cooling that results from using an air source heat pump. Therefore, the WaterUse:Equipment object was removed from the model and replaced with an HPWH consisting of the WaterHeater:HeatPump, WaterHeater:Mixed, and Coil:WaterHeating:AirToWaterHeatPump objects. Schedules of hot water consumption and incoming water temperature were created based on observed data.

Modeling a multi-zone HRV in EnergyPlus is technically challenging due to the fact that a zone can only be served by a single air loop. For this reason, two HRV units were used in the preliminary model, supplying outside air to only the upstairs and downstairs common rooms. This method does accomplish the goal of simulating the supply of outdoor air through a heat exchanger, however, it does not capture the additional mixing that occurs as a result of using an HRV. 
Therefore, a "dummy" cooling system was included in the model that makes use of an outdoor air system coupled with a heat exchanger. The dummy system uses a cooling coil that is always turned off and a mixer that mixes the return air from each zone prior to passing it through the heat exchanger. One important difference between the actual HRV and modeled HRV is in the way air is supplied to and exhausted from the various zones. In the actual system, supply ducts are located in the second floor living room and all three bedrooms while exhaust ducts are located in the bathrooms and kitchen. In the model, a supply and exhaust duct is located in each zone. It is also important to note that this method of modeling the HRV is only used for the West Unit and is only possible because active cooling was not used during the analysis period.

Figure 2.11 compares the corrected observed air temperature data of the second floor West Unit Common Room to that projected by the simulated building after the above changes were made to the model. One can see that the model temperatures closely match the observed temperatures. The RMSE for hourly average zone temperature was reduced to $1.6^{\circ} \mathrm{C}$. Table 2.3 shows the RMSE for hourly average zone temperature, daily minimum and maximum temperatures, and daily average temperature for the analysis period. 


\begin{tabular}{|c|c|c|}
\hline Field & Units & Obj1 \\
\hline Name & & Natural Vent 1st West \\
\hline Zone or ZoneList Name & & 1rstFloor:WestLivingRm \\
\hline Schedule Name & & West Natural Vent \\
\hline Design Flow Rate Calculation Method & & AirChanges/Hour \\
\hline Design Flow Rate & $\mathrm{m} 3 / \mathrm{s}$ & \\
\hline Flow Rate per Zone Floor Area & $\mathrm{m} 3 / \mathrm{s}-\mathrm{m} 2$ & \\
\hline Flow Rate per Person & $\mathrm{m} 3 / \mathrm{s}$-person & \\
\hline Air Changes per Hour & $1 / \mathrm{hr}$ & 0.5 \\
\hline Ventilation Type & & Natural \\
\hline Fan Pressure Rise & $\mathrm{Pa}$ & 0 \\
\hline Fan Total Efficiency & & 1 \\
\hline Constant Term Coefficient & & 1 \\
\hline Temperature Term Coefficient & & 0 \\
\hline Velocity Term Coefficient & & 0 \\
\hline Velocity Squared Term Coefficient & & 0 \\
\hline Minimum Indoor Temperature & C & 15 \\
\hline \multicolumn{3}{|l|}{ Minimum Indoor Temperature Schedule Name } \\
\hline Maximum Indoor Temperature & C & 24 \\
\hline \multicolumn{3}{|l|}{ Maximum Indoor Temperature Schedule Name } \\
\hline Delta Temperature & deltaC & -100 \\
\hline \multicolumn{3}{|l|}{ Delta Temperature Schedule Name } \\
\hline Minimum Outdoor Temperature & C & 10 \\
\hline \multicolumn{3}{|l|}{ Minimum Outdoor Temperature Schedule Name } \\
\hline Maximum Outdoor Temperature & C & 26 \\
\hline \multicolumn{3}{|l|}{ Maximum Outdoor Temperature Schedule Name } \\
\hline Maximum Wind Speed & $\mathrm{m} / \mathrm{s}$ & 10 \\
\hline
\end{tabular}

\begin{tabular}{|l|l|l|}
\hline Field & Units & Obj1 \\
\hline Name & & $\begin{array}{l}\text { Natural Vent 1st West Living } \\
\text { 1rstFloor:WestLivingRm }\end{array}$ \\
\hline Zone or ZoneList Name & & Fenestration Down \\
Schedule Name & & \\
\hline Design Flow Ranges/Hour
\end{tabular}

Figure 2.10. Ventilation assumptions in the original model (top) and the updated model (bottom). 


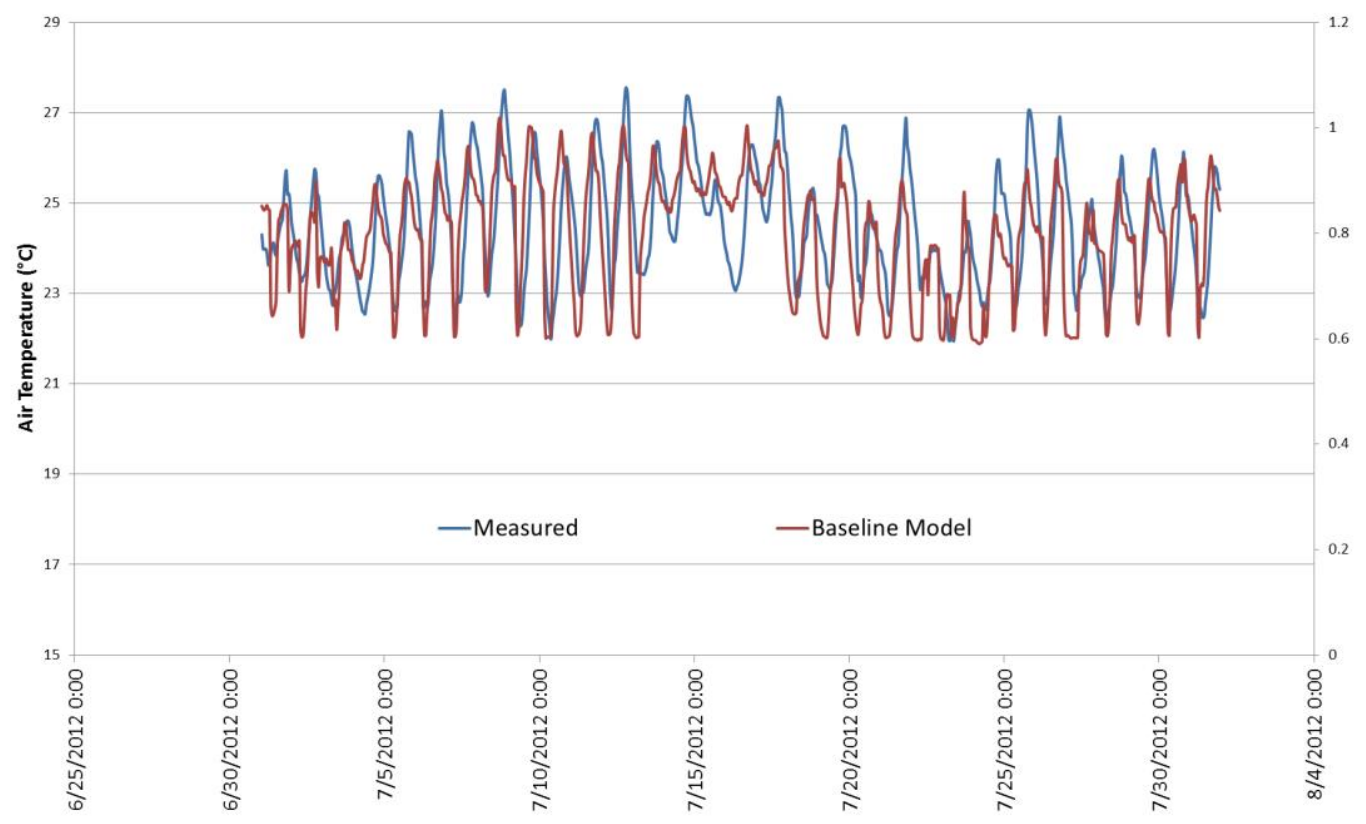

Figure 2.11. Comparison of the West Unit second floor common room air temperature as measured and as projected by the refined model. The refined model predicts the zone air temperature profile fairly well.

Table 2.3. Calculated Root Mean Square Error (RMSE) for the refined Trekhaus EnergyPlus model.

\begin{tabular}{|l|r|}
\hline Hourly Average Temperature, $\operatorname{RMSE}\left({ }^{\circ} \mathrm{C}\right)$ & 1.59 \\
\hline Daily Average Temperature, $\operatorname{RMSE}\left({ }^{\circ} \mathrm{C}\right)$ & 1.15 \\
\hline Daily Minimum Temperture, $\operatorname{RMSE}\left({ }^{\circ} \mathrm{C}\right)$ & 1.06 \\
\hline Daily Maximum Temperture, $\operatorname{RMSE}\left({ }^{\circ} \mathrm{C}\right)$ & 0.97 \\
\hline
\end{tabular}

\subsubsection{Major components, assumptions, and limitations}

All surfaces used in the model were constructed based on information

from the actual building and the PHPP spreadsheet used in the design of the building. Windows were modeled based on detailed glazing information from the manufacturer. Observed data were used to create hourly schedule files for lighting, internal electric equipment, natural ventilation, hot water consumption, cold water supply temperatures, and window blind usage. 
The simulation uses the ConductionFiniteDifference heat balance algorithm with a space discretization constant of 3 and 60 timesteps per hour. Solar distribution is assumed to be Full Exterior. Surface convection algorithms for the interior walls, ceilings and floors are set to ASHRAEVerticalWall, AlamdariHammondStableHorizontal, and AlamdariHammondUnstableHorizontal, respectively. The surface convection algorithm for the interior surfaces of external windows is set to ISO15099Windows. Both units are assumed to be occupied by two adults, 23 hours per day.

Due to EnergyPlus' limitation of a single shading layer per window, it is not possible to model operable windows with both an exterior insect screen and an interior window blind. Therefore, all operable windows are modeled with only an exterior screen while fixed windows are modeled with only an interior blind.

As mentioned previously, simplified models of zone infiltration, zone mixing, and natural ventilation were used in the building simulation. These models are limited in their ability to accurately portray the airflows affecting each zone. Use of EnergyPlus' Airflow Network would perhaps be a better method for modeling these airflows. Additionally, because the window switches used to measure window opening are binary, the degree to which a window is open is not known. A window that is open only a few centimeters would provide the same signal to the data acquisition unit as a window that is completely open. This could potentially be a significant factor in natural ventilation flow rate. 


\subsection{Analysis Approach}

\subsubsection{Analysis Overview}

The analysis portion of this study is divided into two general categories: analysis of observed data and analysis of simulated data from the validated energy model. The analysis period runs from July 1, 2012 through September 30, 2012. This represents the main cooling season in Portland and both indoor and outdoor temperatures reach their annual peak during this period.

\subsubsection{Analysis of observed data}

The data set was first sorted by timestamp and scanned for missing records. For the analysis period, no missing records were found in either the East Unit or West Unit data sets. Data were then plotted to compare various air and surface temperatures, including the temperature of the PCM pouches. Considering the goal of the analysis was to evaluate the effect of PCM in situ, the second floor living room temperatures were of particular interest, especially in the West Unit. Periods where the indoor air temperature surpassed $25^{\circ} \mathrm{C}$ (the melt temperature of the installed PCM) were also of interest and analyzed in greater detail.

\subsubsection{PCM experimentation with validated energy model}

Using a validated energy model to aid in the analysis of the data has some distinct advantages. Mainly, it allows one to investigate "what if" scenarios that are not necessarily practical in a physical building, especially if it is occupied. 
In this regard, the validated energy model of Trekhaus was used to further quantify the performance of the PCM as installed in the physical building. However, it is important to remember that a model is inherently a simplified representation of the actual building and that one must consider the underlying assumptions when drawing conclusions from simulated data.

Three scenarios were evaluated using the validated model to further quantify the effect of PCM in the Trekhaus. The first scenario is a simulation of the building with all PCM removed. This scenario, when compared to the baseline model, directly shows the effect that PCM has on zone temperature and, thus, thermal comfort. The second scenario is a simulation of the building with a PCM melt temperature of $23^{\circ} \mathrm{C}$ instead of $25^{\circ} \mathrm{C}$. This scenario helps to determine if a melt temperature of $25^{\circ} \mathrm{C}$ is optimal. The experimental melt temperature of $23^{\circ} \mathrm{C}$ was chosen for two reasons. First, it is one of the three standard melt temperatures offered in the BioPCM ${ }^{\mathrm{TM}}$ product line. Second, analysis of the observed data indicates that the temperature of the installed BioPCM $25^{\mathrm{TM}}$ was virtually always below $27^{\circ} \mathrm{C}$, so BioPCM $27^{\mathrm{TM}}$ would have little opportunity to complete the melt-freeze cycle. The third scenario is a simulation of the building with the PCM layer moved to the interior surface of the interior walls, where it is the first layer to interact with the zone air. This scenario helps to determine if the current installation method of attaching the PCM to the studs behind the gypsum board hinders its ability to moderate zone air temperature. Each scenario used a run period from June 1, 2012 to September 30, 2012 and 
the results were compared to the baseline model for the analysis period, July 1 , 2012 to September 30, 2012. 


\section{Results}

The results of this study are presented in two sections: observed data and simulated data. The air and wall surface temperatures in the second floor common room of each unit are of particular interest, as the majority of installed PCM is located in the West Unit Common Room.

\subsection{Observed Data}

A summary of observed air and surface temperatures in the East and West Unit second floor Common Rooms is presented in Table 3.1. Data from the surface temperature thermocouple in Position 4 of the West Unit is not presented, as it was damaged during construction. Additionally, peak temperatures measured by the Position 3 thermocouple in the West Unit are abnormally high, suggesting that it was either damaged during construction or that waste heat from a nearby appliance caused an elevated surface temperature measurement. Therefore, data from these two sensor positions (3 and 4) will not be included in the remaining presentation of results, with the exception of the temperatures measured by the sensors embedded in the PCM pouches.

During the analysis period, the maximum indoor air temperature observed in the second floor East and West Common Rooms was $29.7^{\circ} \mathrm{C}$ and $29.5^{\circ} \mathrm{C}$, respectively. Both of these peak temperatures were observed on August 17 and a maximum outdoor air temperature of $38.1^{\circ} \mathrm{C}$ was observed on August 
16. Figure 3.1 compares the observed East and West Unit air temperatures for the period from August 14 to August 20. This includes three days prior to and three days after the date of the maximum observed indoor air temperature. For this same period, Figure 3.2Figure 3.3 compare the East and West Unit Position 1 and 2 surface temperatures, Figure 3.4 shows the observed temperatures of the PCM in Positions 1-4, and Table 2 provides a summary of the observed PCM temperatures. Note that the shaded area in each figure indicates the approximate melting range of the $\mathrm{BioPCM}^{\mathrm{TM}}$. 
Table 3.1. Observed average, minimum and maximum temperatures in the East Unit's second floor Common Room.

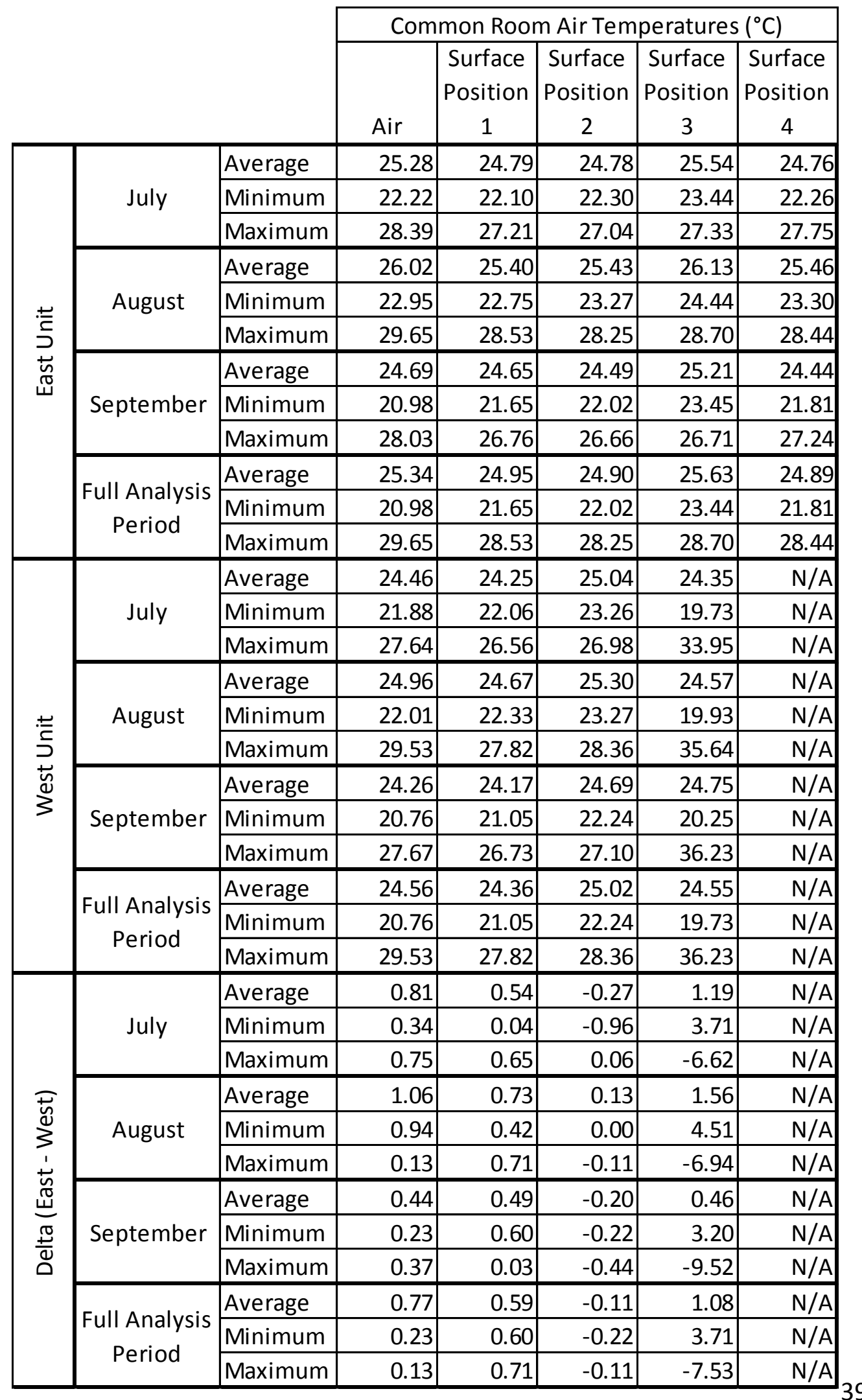




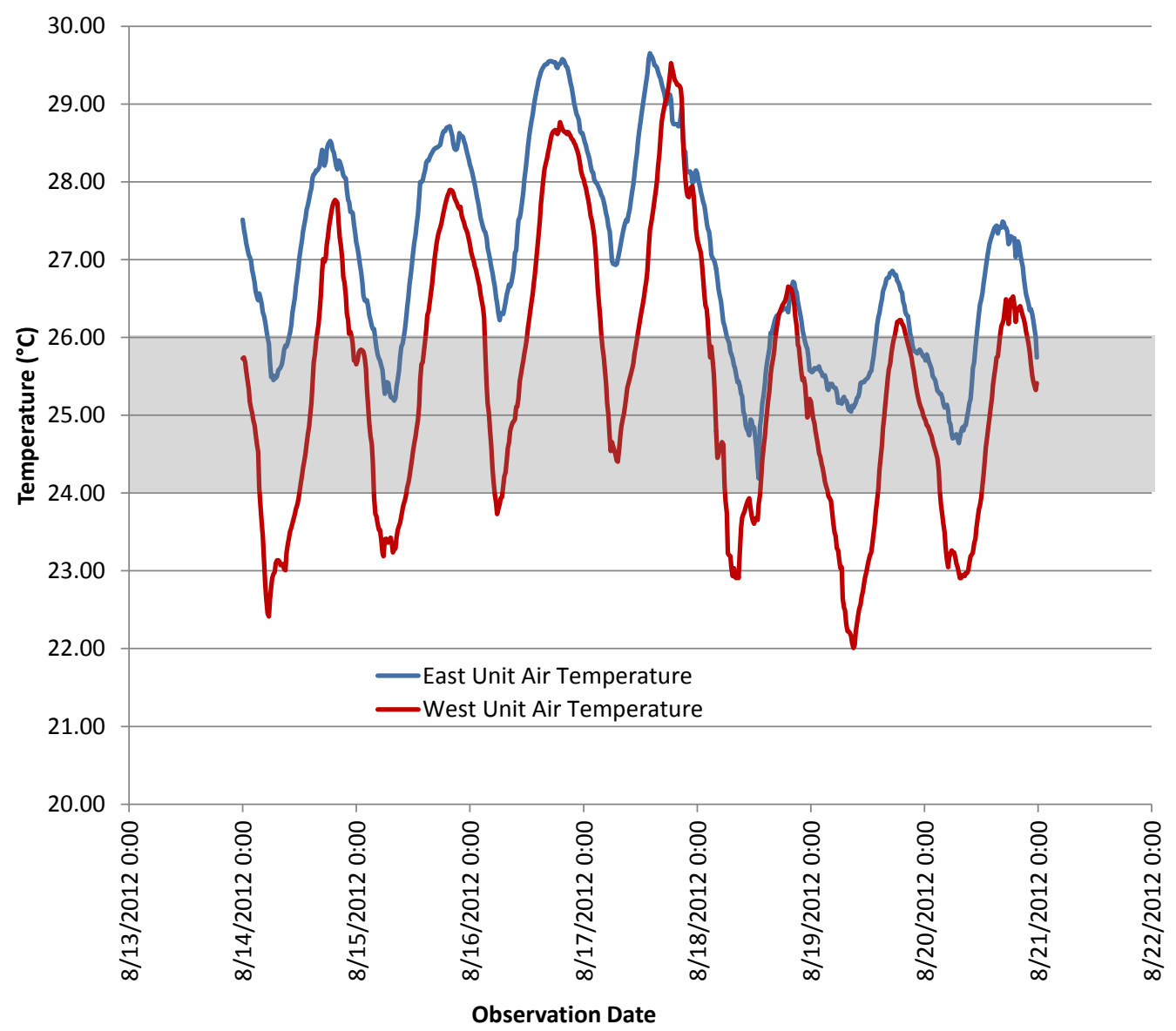

Figure 3.1. Observed air temperatures of the East and West Unit second floor Common Rooms in the warmest week observed during the analysis period. 


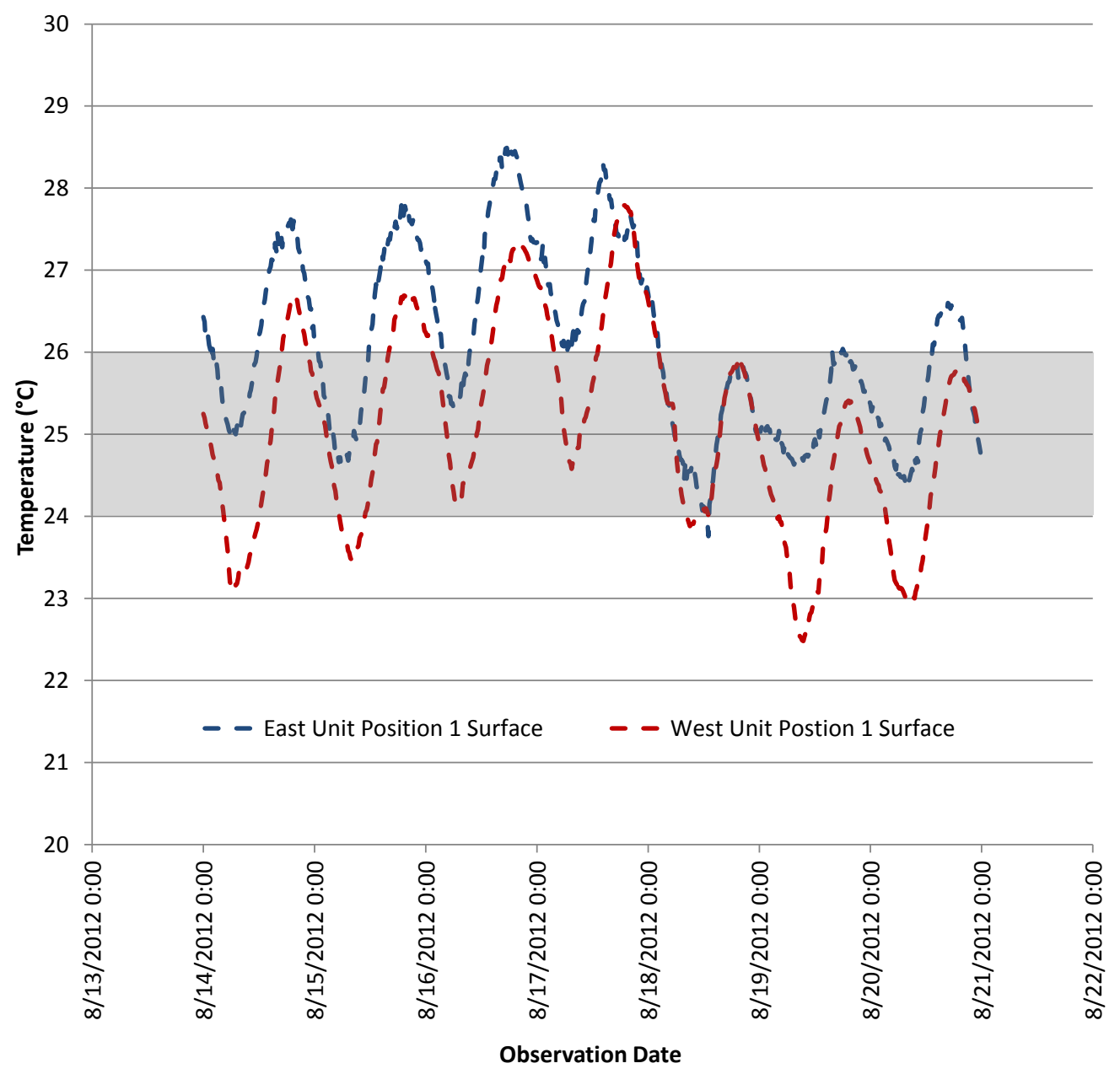

Figure 3.2. Observed surface temperatures in Position 1 for the East and West Unit second floor Common Room. 


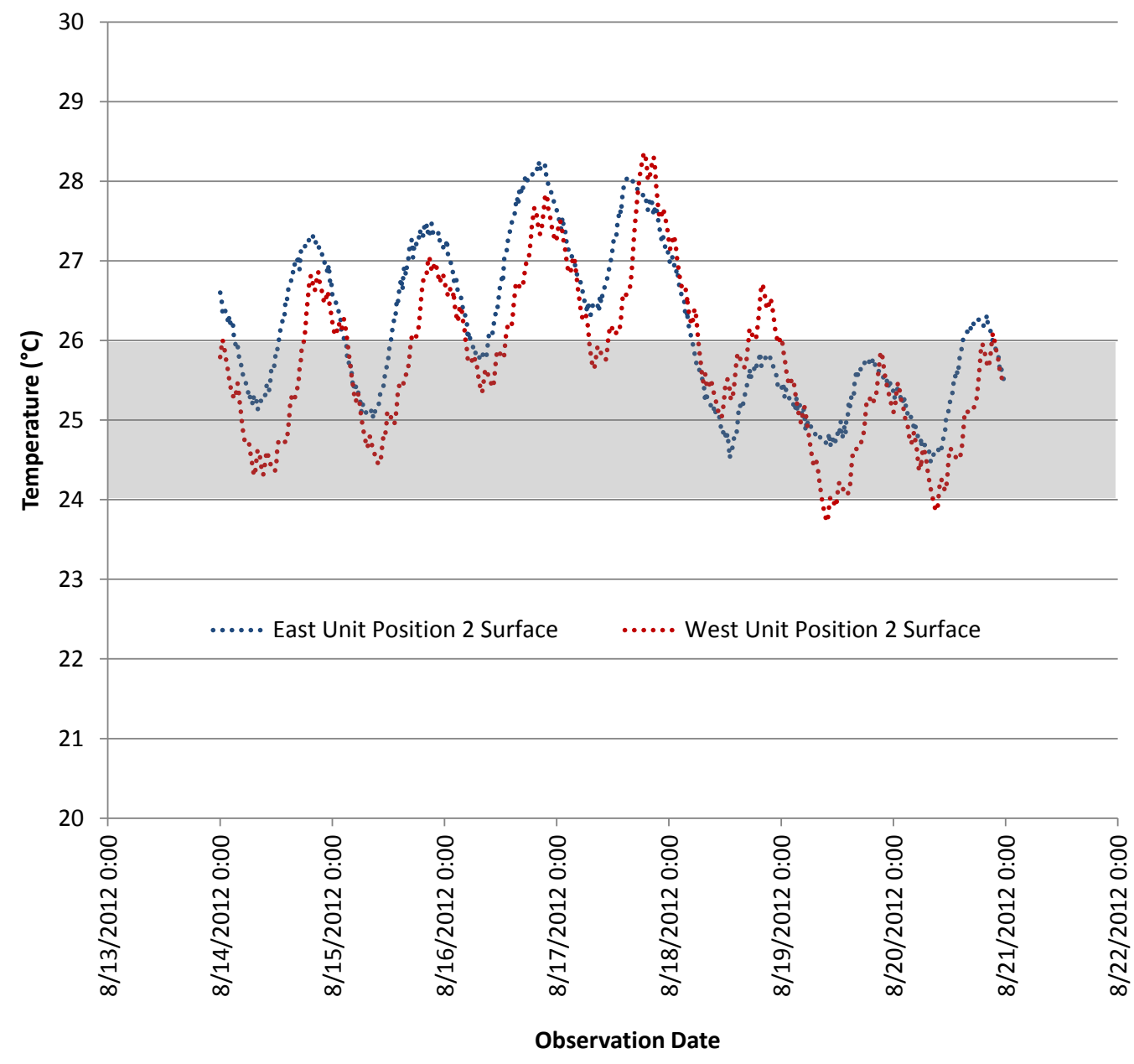

Figure 3.3. Observed surface temperatures in Position 2 for the East and West Unit second floor Common Room.

Table 3.2. Observed average, minimum, and maximum temperatures of PCM in Positions 1-4.

\begin{tabular}{|c|c|c|c|c|c|}
\hline & \multicolumn{4}{|c|}{ PCM Temperature $\left({ }^{\circ} \mathrm{C}\right)$} \\
\hline & & \begin{tabular}{|c|} 
Position \\
1
\end{tabular} & \begin{tabular}{|c|} 
Position \\
2
\end{tabular} & \begin{tabular}{|c|} 
Position \\
3
\end{tabular} & $\begin{array}{c}\text { Position } \\
4\end{array}$ \\
\hline \multirow{3}{*}{ July } & Average & 24.14 & 24.35 & 24.75 & 24.10 \\
\hline & Minimum & 22.03 & 22.52 & 23.44 & 21.93 \\
\hline & Maximum & 25.98 & 25.97 & 25.82 & 25.64 \\
\hline \multirow{3}{*}{ August } & Average & 24.58 & 24.71 & 25.01 & 24.27 \\
\hline & Minimum & 22.31 & 22.77 & 23.48 & 22.32 \\
\hline & Maximum & 27.00 & 26.76 & 26.75 & 26.50 \\
\hline \multirow{3}{*}{ September } & Average & 24.08 & 24.15 & 24.40 & 23.74 \\
\hline & Minimum & 21.04 & 21.27 & 22.38 & 21.31 \\
\hline & Maximum & 27.00 & 26.76 & 26.75 & 26.50 \\
\hline \multirow{3}{*}{$\begin{array}{c}\text { Full Analysis } \\
\text { Period }\end{array}$} & Average & 24.27 & 24.40 & 24.72 & 24.04 \\
\hline & Minimum & 21.04 & 21.27 & 22.38 & 21.31 \\
\hline & Maximum & 27.00 & 26.76 & 26.75 & 26.50 \\
\hline
\end{tabular}




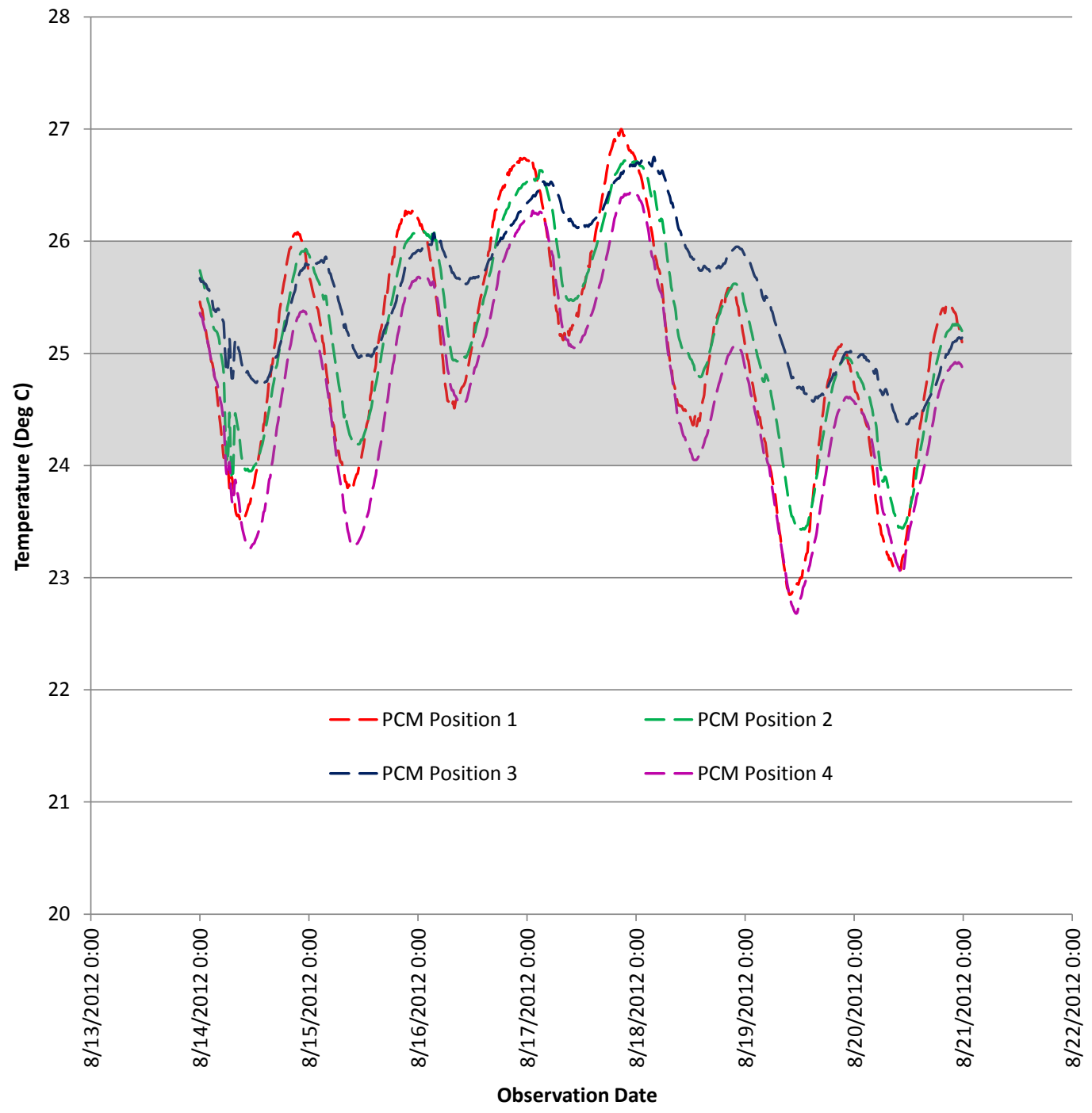

Figure 3.4. Observed temperatures of the PCM in Positions 1-4 during the warmest week of the analysis period, August 14-20. Note that the temperatures to do not "flatten out" at the melt temperature. 


\subsection{Results of Simulation Study}

For the period from August 14 to August 20, Figure 3.5, Figure 3.6, and Figure 3.7 compare the baseline model to the model with PCM removed, the model with a $23^{\circ} \mathrm{C}$ melt temperature, and the model with the PCM moved to the interior surface of the wall, respectively. Figure 3.8 shows all four scenarios together and Figure 3.9 compares the time outside thermal comfort for each scenario. It is interesting to note that Campbell and Sailor projected 245 zone hours overheated in the scenario without PCM while the results of the present study project 436 hours overheated in the same scenario. This difference is likely due to differences in the assumptions made regarding internal gains. Likewise, Campbell and Sailor projected fewer hours overheated in the cases using PCM melt temperatures of $23^{\circ} \mathrm{C}$ and $25^{\circ} \mathrm{C}$, likely due to differences in internal gains and a slightly lower PCM application density in the present study $\left(1.3 \mathrm{~kg} / \mathrm{m}^{2} \mathrm{vs}\right.$. $\left.0.9 \mathrm{~kg} / \mathrm{m}^{2}\right)$. 


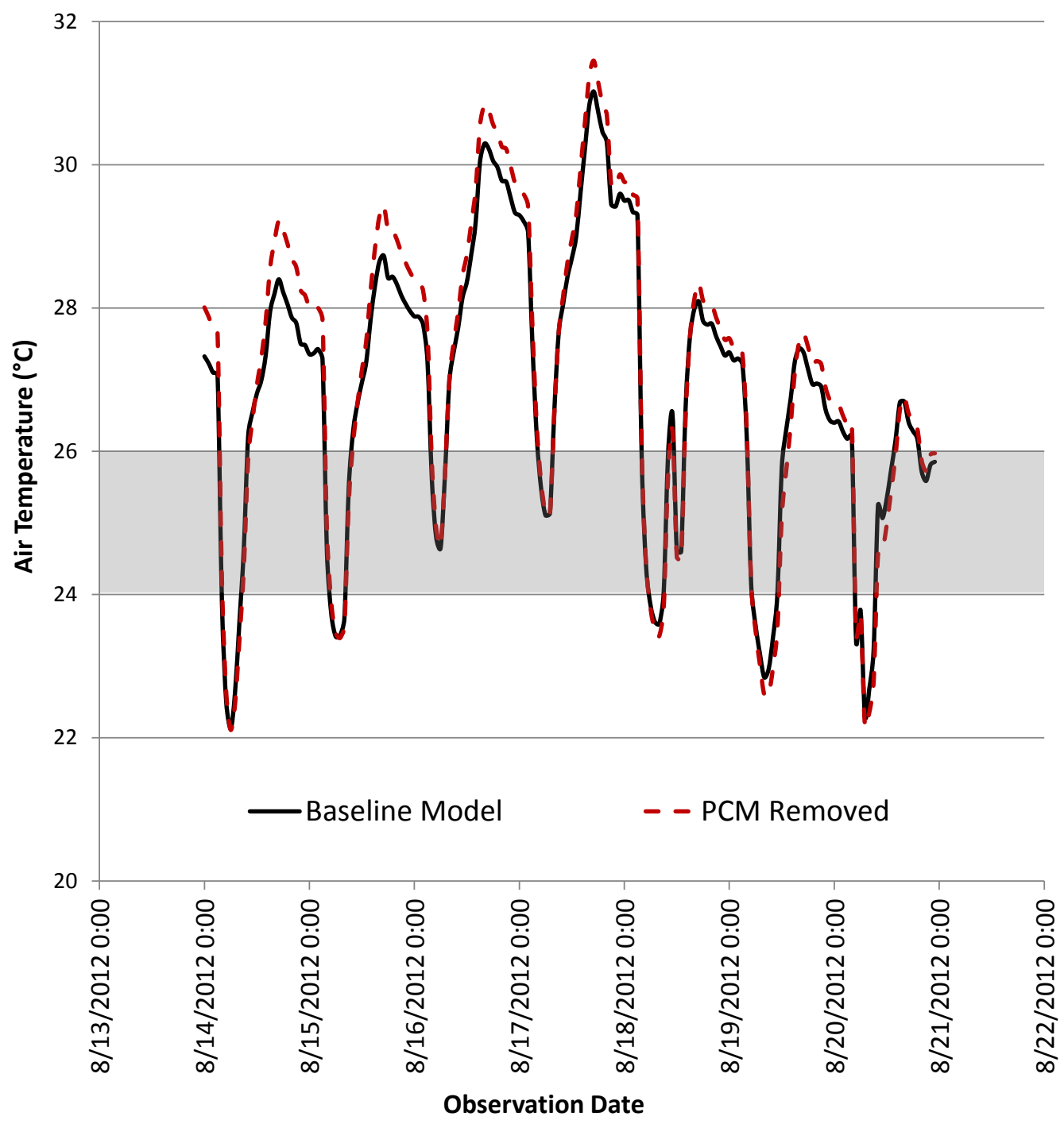

Figure 3.5. Comparison of the Baseline Model and the model with all PCM removed during the warmest week of the analysis period. Note that the Baseline Model has a lower peak temperature for the first four days, but is virtually the same as the model with no PCM in the last three days. 


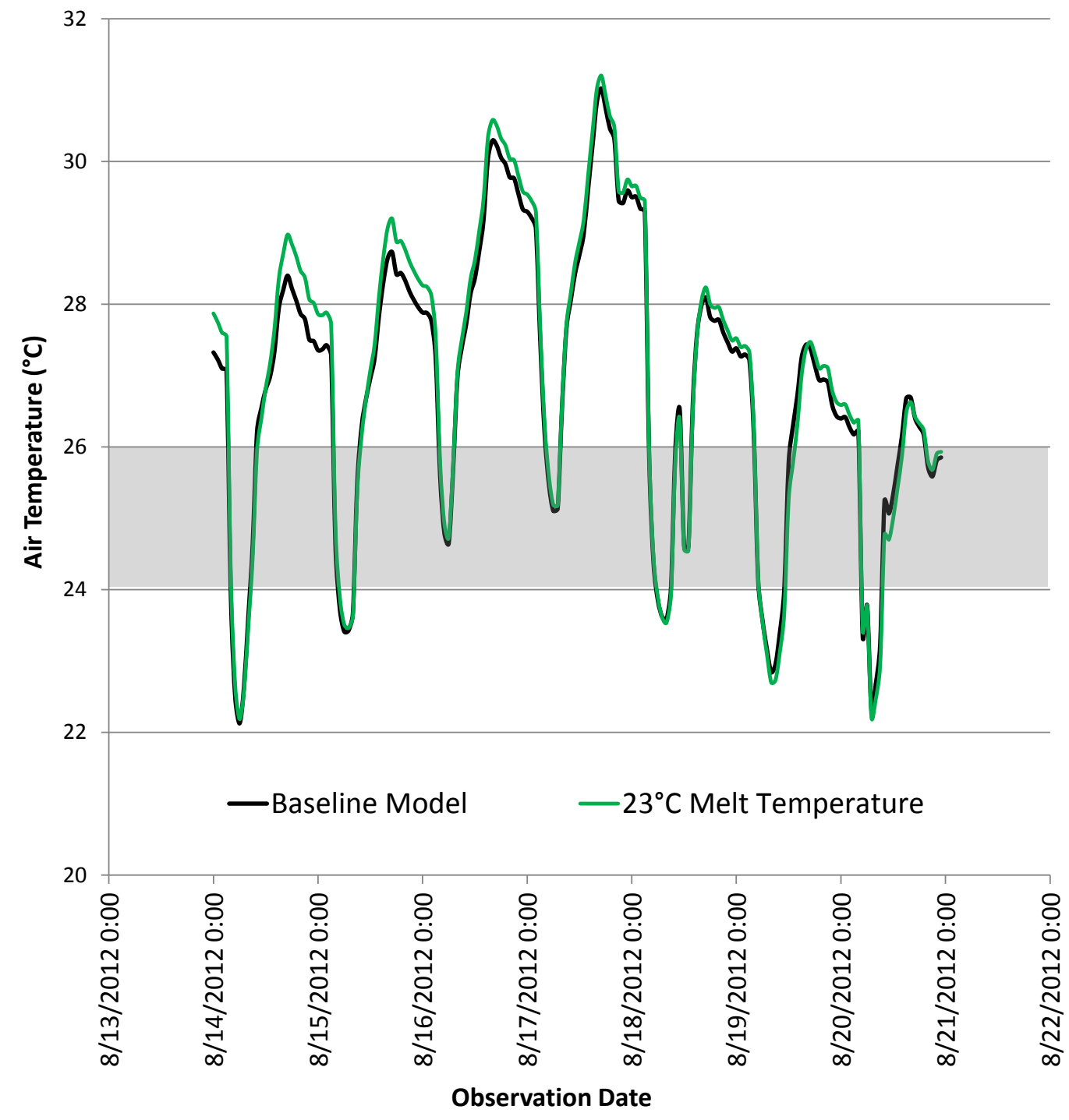

Figure 3.6. Comparison of the Baseline Model and the model with a $23^{\circ} \mathrm{C}$ melt temperature during the warmest week of the analysis period. Note that the peak temperatures in the baseline model are lower in the first four days. 


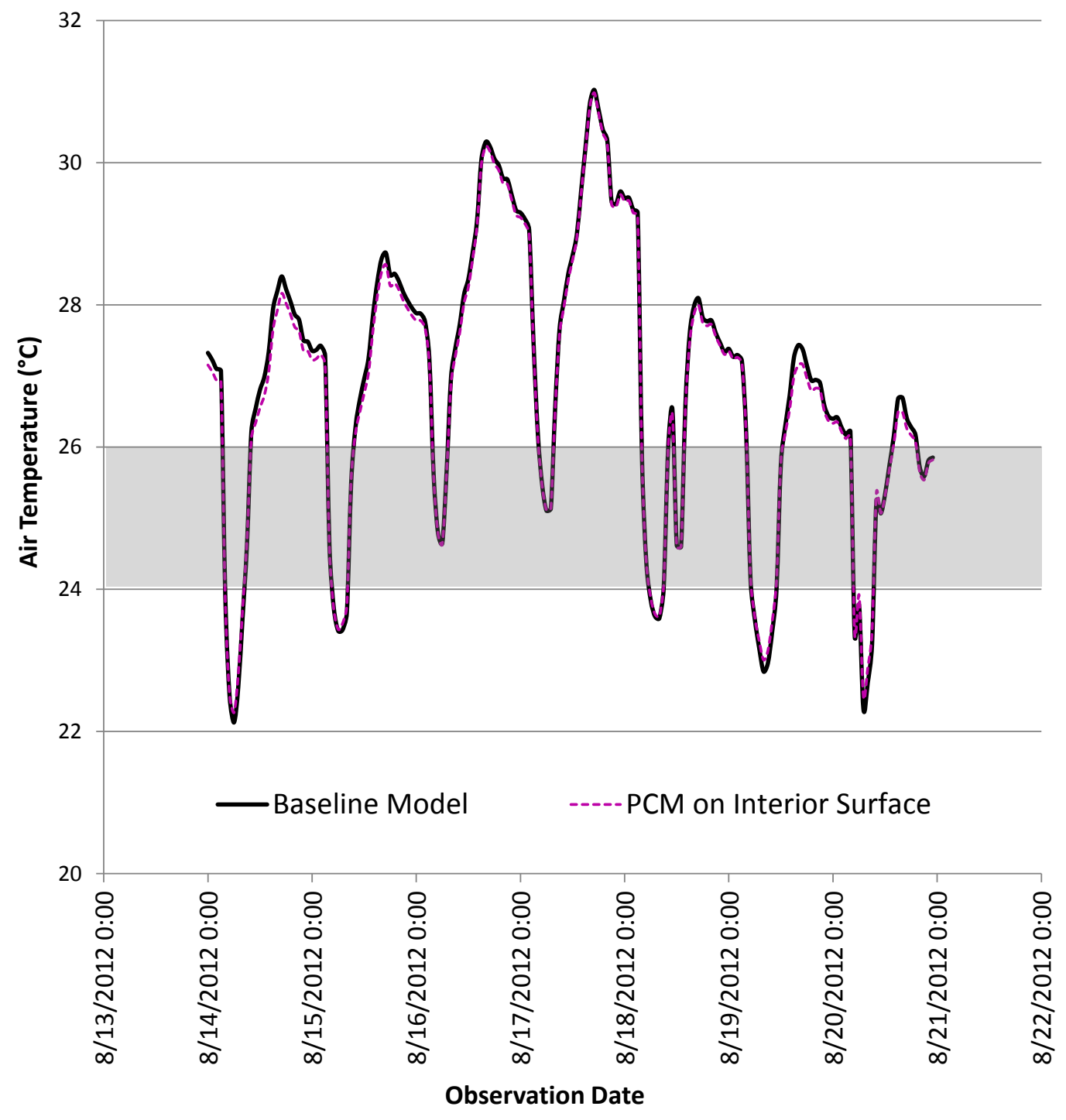

Figure 3.7. Comparison of the Baseline Model and the model with the PCM moved to the interior wall surface during the warmest week of the analysis period. Note that relocating the PCM to the interior surface had very little impact to the peak temperatures. 


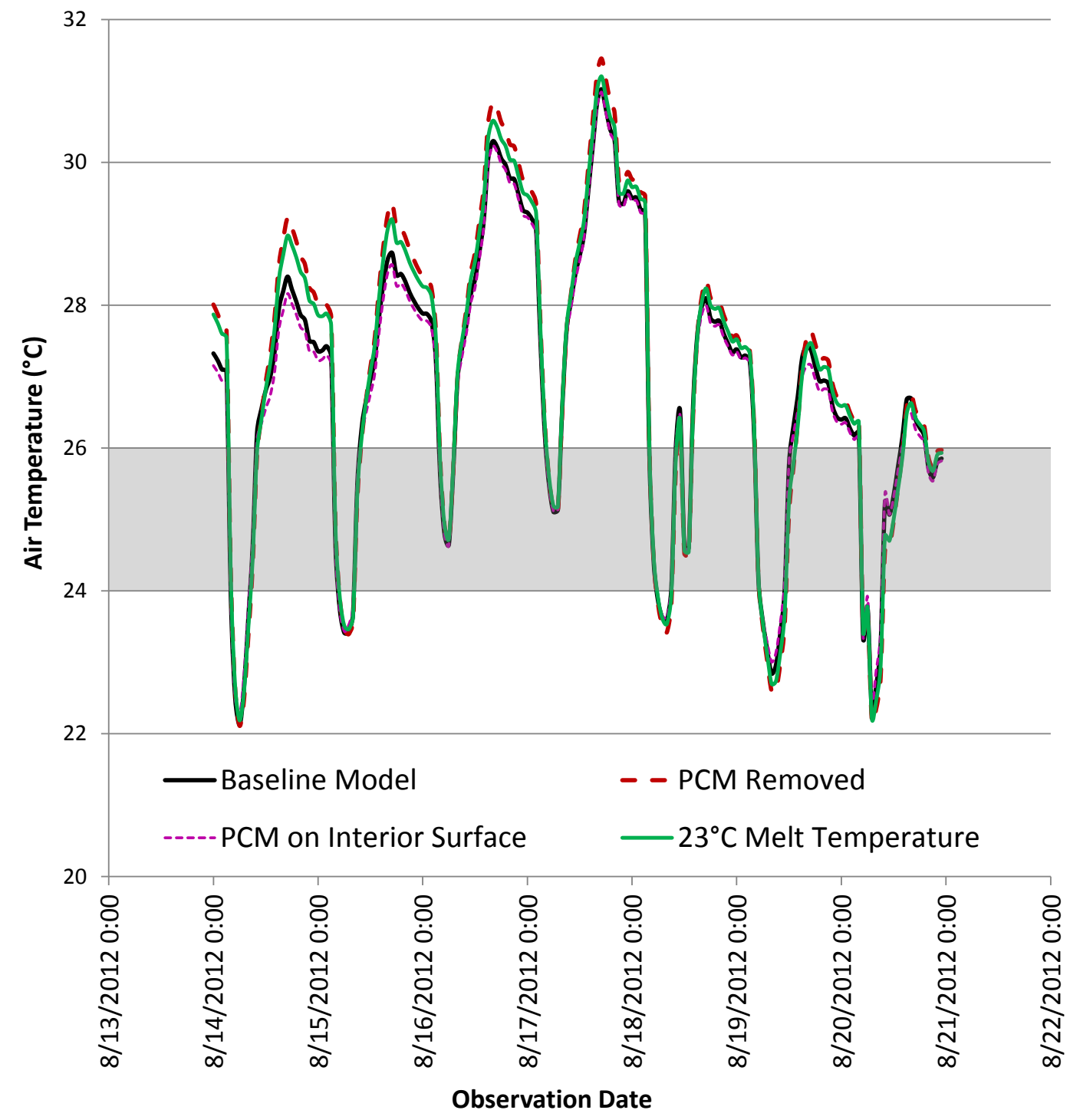

Figure 3.8. Comparison of all four simulations together. Note that removing the PCM caused the largest increase in peak temperatures.

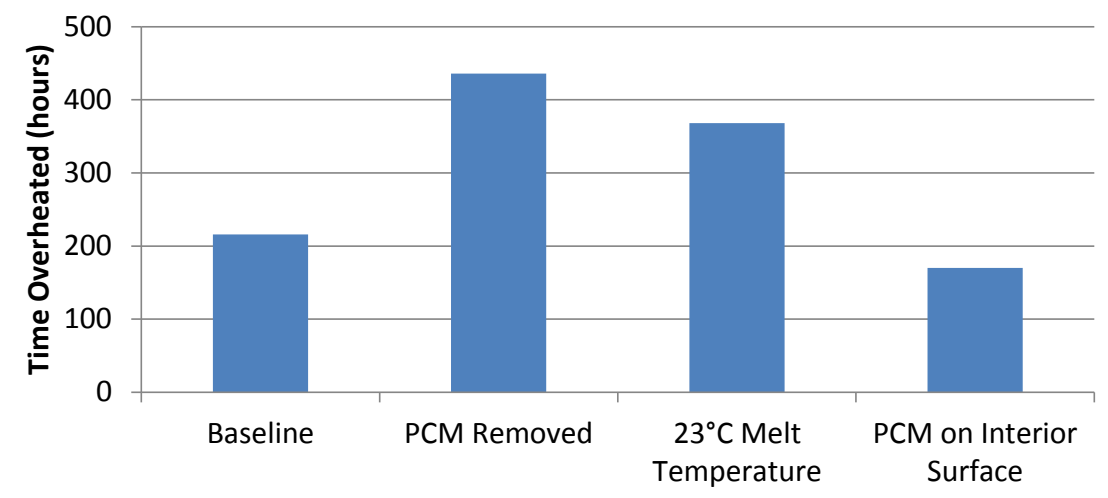

Figure 3.9. Number of hours overheated in each of the simulated scenarios. 


\section{Discussion}

4.1 PCM performance - measured and modeled

\subsubsection{Analysis of Observed Data}

Table 3.1 and indicates that the average air temperature in the West Unit was $0.77^{\circ} \mathrm{C}$ lower than that of the East Unit during the analysis period. The average air temperature in the West Unit during the month of August, the warmest month of the year, was $1.06^{\circ} \mathrm{C}$ cooler than the East Unit. Additionally, Figure 3.1-3.3 suggest that both air and surface temperatures might typically be lower in the West Unit. However, while the average Position 1 surface temperature was lower in the West Unit, the average Position 2 surface temperature in the West Unit was higher than that of the East, albeit by only $0.11^{\circ} \mathrm{C}$.

As seen in Table 3.2, the thermocouples embedded in the PCM pouches measured a minimum temperature of $21.0^{\circ} \mathrm{C}$ and a maximum temperature of $27.0^{\circ} \mathrm{C}$ during the analysis period. Further analysis indicates that the PCM temperatures generally fluctuated between $23.2^{\circ} \mathrm{C}$ and $25.5^{\circ} \mathrm{C}$. The BioPCM ${ }^{\mathrm{TM}}$ enthalpy curve suggests that the majority of melting occurs between $24^{\circ} \mathrm{C}$ and $26^{\circ} \mathrm{C}$ (Figure 1.5), which implies that the PCM rarely melts or freezes completely. During the phase transition, an ideal material's temperature would remain constant at the melt temperature (Figure 1.2). The PCM temperature profiles in Figure 3.4 do not exhibit this behavior, further supporting the implication that 
the PCM is not melting and freezing completely. However, one must consider the fact that ideal materials do not exist in reality and that the phase transition will occur over a small temperature range (Figure 1.5). Additionally, while the research team made every attempt possible to ensure accurate data collection, it is still possible that the PCM temperature measurements do not accurately represent the true PCM temperature in situ. Thermocouples were embedded in the PCM by poking a small hole in a PCM pouch, inserting the thermocouple, and covering the hole with aluminum tape. It is possible that some of the thermocouples have dislodged from the pouches or that some of the PCM has leaked out of the pouches. Either scenario would potentially expose the thermocouple junction and introduce error into the measurement.

While some may be eager to assume that the lower air and surface temperatures in the West Unit are due to the presence of the PCM, it is important to consider all the variables that might influence this result. The building used in the present study is privately owned and occupied by real people. As such, occupant behaviors vary significantly between the East and West Units. For example, Figure 4.1 shows the daily average electricity consumption for both units during the analysis period. The East Unit occupants consumed approximately $4.7 \mathrm{kWh}$ (roughly 63\%) more electricity per day than the West Unit occupants, thus the East Unit had much higher internal gains. Further, the West Unit occupants made use of natural ventilation through window opening more often than the East Unit occupants. Analysis of the data 
provided by installed window switches indicates that the upstairs windows in the West Unit were open approximately $22.5 \%$ of the time, while the East Unit windows were open less than $1 \%$ of the time. Finally, the West Unit occupants made use of the cooling provided by the heat pump water heater in the

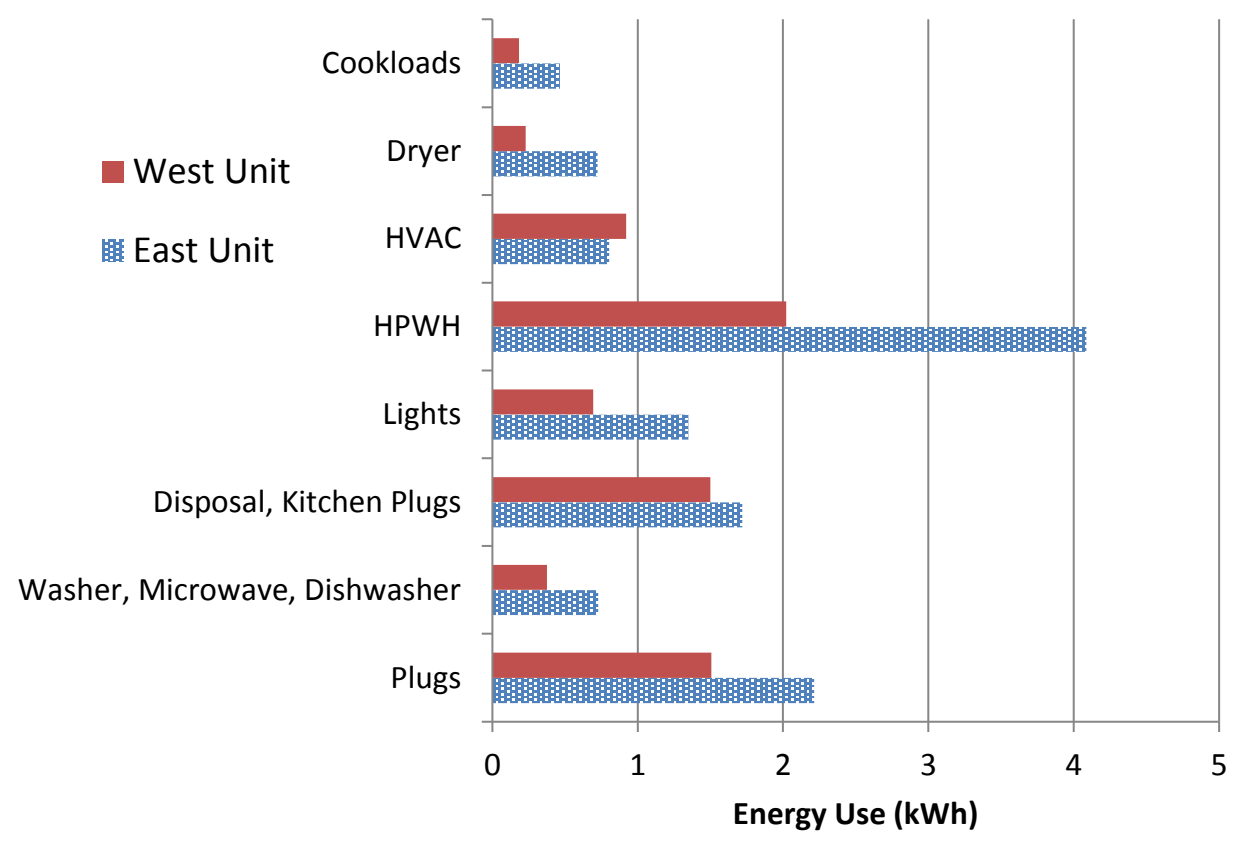

Figure 4.1. Daily average electricity consumption by the East and West occupants during the analysis period.

unconditioned workshop. This is evident based on switch data from the door that separates the workshop and the laundry room, which indicates that the West Unit had the door open approximately $70 \%$ of the time while the East Unit rarely, if ever, opened the door.

When considering these factors, it is not surprising that the air temperature in the West Unit was lower than that of the East Unit. Consequently, the results based solely on the analysis of observed data are largely inconclusive. However, the results of the simulation study provide a little 
more insight into the performance of the BioPCM ${ }^{\mathrm{TM}}$ as installed in Trekhaus.

\subsubsection{Analysis of Simulated Data}

Of the four scenarios simulated, moving the PCM to the surface of the interior walls is the only scenario that offered a reduction in hours outside thermal comfort over the baseline model (Figure 3.9). However, the reduction was rather minimal and only reduced the time outside thermal comfort by about 46 hours. This suggests that the current installation method of installing BioPCM $^{\mathrm{TM}}$ behind the gypsum board is adequate to allow thermal interaction with the space. Removing the PCM altogether resulted in an increase of time overheated by 220 hours, suggesting that the PCM does, in fact, have a positive effect on thermal comfort. Reducing the melt temperature to $23^{\circ} \mathrm{C}$ resulted in an increase of time overheated by 152 hours. This is likely a result of the PCM remaining in the liquid phase more of the time, which would limit its storage capability to sensible heat. This highlights the importance of allowing the PCM to refreeze each night ad further supports the findings of Campbell and Sailor that the largest improvements resulted from using a melt temperature of $25^{\circ} \mathrm{C}$.

Figure 3.5 suggests that removing the PCM from the wall assembly would result in higher air temperatures on several days throughout the summer. However, there are many days where removing the PCM would make virtually no difference to the zone air temperature, including August 17, when the highest indoor air temperature was observed. Considering this peak occurs during a period of elevated outdoor temperature, it is likely that the PCM is completely 
melted and is only capable of storing sensible heat. This further highlights the importance of allowing the PCM to refreeze each night to prepare for the next day's internal heat gains.

\subsection{Comparison to other studies}

Considering the active cooling system was not used during the evaluation period, the results of this study can only be compared to studies that evaluate thermal comfort. Of particular interest is the research by Campbell and Sailor, which is the basis of the present study. Campbell and Sailor [24] found that, in the Portland, Oregon case, the total zone-hours overheated in the baseline model was less than 250 . Further, installing $1.3 \mathrm{~kg}$ of $25^{\circ} \mathrm{C}$ melt PCM per squaremeter floor area reduced the zone hours overheated to less than 150. Observed data from the actual house, which has roughly $0.9 \mathrm{~kg} / \mathrm{m}^{2}$ floor area of $25^{\circ} \mathrm{C}$ melt PCM, suggests the number of hours overheated is approximately 170 . The number of zone hours overheated in the present study's baseline simulation is approximately 216 .

Behzadi and Farid [28] simulated a typical $171-\mathrm{m}^{2}$ house in Auckland, New Zealand and found that the use of PCM-impregnated gypsum board could reduce indoor temperature fluctuation by up to $4^{\circ} \mathrm{C}$ on a typical summer day. Fernandes and Costa [21] used simulation to study the effect of PCM in a typical house in three locations in Portugal. Using gypsum board containing $3 \mathrm{~kg} / \mathrm{m}^{2}$ $25^{\circ} \mathrm{C} \mathrm{PCM}$ on the walls and ceilings, they found that reductions of $24 \%-34 \%$ in 
hours over $25^{\circ} \mathrm{C}$ were possible. Similar to these studies, the results from the present study also suggest that PCM can reduce temperature fluctuation and overheating, but not to the same degree. This may be due to the differences between a typical building and one that is built to meet the Passive House Standard.

\subsection{Potential Drawbacks}

While the data suggests that PCM can play a role in improving thermal comfort, it is important to also consider any potential drawbacks that might be associated with the technology. Installation of the material directly behind the gypsum board leads to the possibility of damaging the pouches that contain the PCM. For example, an unsuspecting occupant who intends to hang a picture on the wall might drive a nail or screw through the gypsum board and rupture one of the pouches containing the PCM. Over time, the PCM could leak out of the pouch and cause cosmetic blemishes to the finish surface. In fact, an in-house study by Pamela Wallace of the Green Building Research Laboratory tested this possibility by puncturing several PCM pouches, attaching the punctured sheets to various finish surfaces, and cycling them through several hot and cold temperature cycles. The results of the study indicate that noticeable cosmetic blemishes are likely when the PCM leaks onto acoustic ceiling tiles. In addition, because BioPCM ${ }^{\mathrm{TM}}$ is made from soy and palm-kernel oil, the potential exists for a ruptured pouch to attract rodents or other pests. However, this hypothesis has 
yet to be tested, nor is the author aware of any documented cases of this occurring.

4.4 What could be done differently?

Although the results of this study suggest that PCM does have a positive effect on thermal comfort, an important question to consider is what changes could be made to further enhance its effectiveness. This is particularly important in the context of a Passive House where little temperature fluctuation occurs, as evidenced by the observed temperatures in the East and West Units. As many studies have noted the importance of allowing the PCM to freeze completely overnight, exploring options to aid in this behavior seems like a logical first step. One possibility to cool the space more at night would be to increase the ventilation rate using a higher setting on the HRV. The HRV includes an option to bypass the heat exchanger to take advantage of free cooling. Without the bypass activated, when the outdoor air temperature falls below the indoor air temperature, the indoor air that is being exhausted from the building will heat the incoming outdoor air. Ensuring that the bypass is activated and increasing the HRV fan speed at night would bring in more outside air and further cool the space. Considering the HRV fans are already being used to provide the necessary ventilation, further utilizing the fans to take advantage of free cooling would be an energy efficient means of cooling the space. This practice would likely be advantageous in buildings with and without PCMs installed. However, care 
should be taken to ensure that the bypass is only activated when the outside air is cooler than the indoor air and space cooling is desired.

Another option to increase the effectiveness of the PCM is to increase the airflow along the surface of the wall that contains the PCM. This would increase the convective heat transfer at the surface, allowing the PCM to dissipate more of its stored heat, which in turn allows it to absorb more heat during the melting phase. In climates with prevailing winds from a certain direction, it may be possible to design the building such that the cross wind would be enough airflow to dissipate the heat in the PCM. A lack of the correct climatic conditions would likely require the use of fans. In this case, the added fan energy and temperature rise across the fan would need to be carefully considered before implementation. 


\section{Conclusion}

This study evaluates the ability of a macro-encapsulated PCM to reduce overheating in a Passive House in Portland, Oregon through the analysis of observed data and building energy simulation. The building energy model was first validated using observed data and then used to test the effect of removing the PCM, changing the $\mathrm{PCM}$ melt temperature to $23^{\circ} \mathrm{C}$, and moving the $\mathrm{PCM}$ layer to the interior surface of the wall. While the results of the field-measured data are largely inconclusive, the results of the energy simulation indicate that the incorporation of $0.9 \mathrm{~kg} / \mathrm{m}^{2}$ of $\mathrm{PCM}$ with a melt temperature of $25^{\circ} \mathrm{C}$ is capable of reducing the zone hours overheating from 436 to 216 . Additionally, reducing the melt temperature of the $\mathrm{PCM}$ to $23^{\circ} \mathrm{C}$ resulted in an increase of 152 zone hours overheating, from 216 to 368 . Finally, changing the location of the PCM to the interior wall surface resulted in a reduction of 46 zone hours overheating, from 216 to 170 .

The results of this study highlight the importance of allowing the PCM to refreeze each night to increase its heat storage capabilities the following day. Whether this is accomplished through mechanical cooling, mechanical ventilation, or natural ventilation depends on the climate and design characteristics of the building.

Since this study was focused only on the summer months, the EnergyPlus model needs further validation for the remaining nine months of the year. In 
order to do this, the HVAC system would need to be reconfigured to include the heat pump. This could be accomplished by incorporating a heat pump as zone equipment in the first- and second-floor common rooms. Further improvement of the model could be made through the incorporation of the moresophisticated Airflow Network models for natural ventilation. Additionally, using design of experiments, the peak temperature offset should be further analyzed to investigate surface convection algorithms, solar distribution, PCM contact resistance, internal gains, and other variables. With an improved model, additional experimentation of the PCM would be the next logical step, including the investigation of non-standard PCM melt temperatures. 


\section{References}

[1] United States Department of Energy (US DOE). United States. (2011). Buildings energy data book. Available: http://www.btscoredatabook.net

[2] K. Ripley. IBISWorld Industry Report OD4674. Green \& Sustainable Building Construction [Online]. Available:

http://clients1.ibisworld.com/reports/us/industry/default.aspx?entid=4674

[3] W. Feist, "Passipedia," ed. Darmstadt, Germany: Passive House Institute. Available: http://passipedia.passiv.de

[4] Passive House Institute US, "What is a Passive House?", 2011. Available: http://www.passivehouse.us/passiveHouse/PassiveHouselnfo.html

[5] W. Feist, "PHPP: Far More Than Just An Energy Calculation Tool." 2007. Available: http://www.passivhaustagung.de/Passive_House_E/PHPP.html

[6] J. Mlakar and J. Strancar, "Overheating in residential passive house: Solution strategies revealed and confirmed through data analysis and simulations," Energy and Buildings, vol. 43, pp. 1443-51, 06/ 2011.

[7] V. Badescu, N. Laaser, and R. Crutescu, "Warm season cooling requirements for passive buildings in Southeastern Europe (Romania)," Energy, vol. 35, pp. 3284-3300, 2010.

[8] W. Feist, J. Schnieders, V. Dorer, and A. Haas, "Re-inventing air heating: Convenient and comfortable within the frame of the Passive House concept," Energy and Buildings, vol. 37, pp. 1186-1203, 11/2005.

[9] M. Orme and J. Palmer, "Control of overheating in future housing-design guidance for low energy strategies," FaberMaunsell, St Albans, 2003.

[10] J. Kosny, T. Petrie, D. Gawin, P. Childs, A. Desjarlais, and J. Christian, "Thermal Mass - Energy Savings Potential in Residential Buildings," ed. Oak Ridge, Tennessee: Oak Ridge National Labs, 2001.

[11] United States Department of Energy (US DOE). United States, Alternatives to lumber and plywood in home construction. Washington, D.C.: 1993.

[12] Z. Na, M. Zhenjun, and W. Shengwei, "Dynamic characteristics and energy performance of buildings using phase change materials: a review," Energy Conversion and Management, vol. 50, pp. 3169-81, 12/ 2009. 
[13] H. Liu and H. B. Awbi, "Performance of phase change material boards under natural convection," Building and Environment, vol. 44, pp. 1788-1793, 2009.

[14] R. Baetens, B. Jelle, and A. Gustavsen, "Phase change materials for building applications: A state-of-the-art review," Energy and Buildings, vol. 42, pp. 1361-8, 2010.

[15] F. Kuznik, D. David, K. Johannes, and J. J. Roux, "A review on phase change materials integrated in building walls," Renewable and Sustainable Energy Reviews, vol. 15, pp. 379-91, 01/2011.

[16] A. Pasupathy, R. Velraj, and R. V. Seeniraj, "Phase change material-based building architecture for thermal management in residential and commercial establishments," Renewable and Sustainable Energy Reviews, vol. 12, pp. 39-64, 01/2008.

[17] L. F. Cabeza, C. Castellon, M. Nogues, M. Medrano, R. Leppers, and O. Zubillaga, "Use of microencapsulated PCM in concrete walls for energy savings," Energy and Buildings, vol. 39, pp. 113-119, 2007.

[18] S. Shrestha, W. Miller, T. Stovall, A. Desjarlais, K. Childs, W. Porter, et al., "Modeling PCM-enhanced insulation system and benchmarking EnergyPlus against controlled field data," in 12th Conference of International Building Performance Simulation Association Building Simulation 2011, BS 2011, November 14, 2011 - November 16, 2011, Sydney, NSW, Australia, 2011, pp. 800807.

[19] A. M. Borreguero, M. Carmona, M. L. Sanchez, J. L. Valverde, and J. F. Rodriguez, "Improvement of the thermal behaviour of gypsum blocks by the incorporation of microcapsules containing PCMS obtained by suspension polymerization with an optimal core/coating mass ratio," Applied Thermal Engineering, vol. 30, pp. 1164-1169, 2010.

[20] E. Rodriguez-Ubinas, L. Ruiz-Valero, S. Vega, and J. Neila, "Applications of Phase Change Material in highly energy-efficient houses," Energy and Buildings, vol. 50, pp. 49-62, 2012.

[21] N. T. A. Fernandes and V. A. F. Costa, "Use of phase-change materials as passive elements for climatization purposes in summer: the Portuguese case," International Journal of Green Energy, vol. 6, pp. 302-11, 05/ 2009.

[22] J. Persson and M. Westermark, "Phase change material cool storage for a Swedish Passive House," Energy and Buildings, vol. 54, pp. 490-495, 2012. 
[23] K. Muruganantham, P. Phelan, P. Horwath, D. Ludlam, and T. McDonald, "Experimental investigation of a bio-based phase-change material to improve building energy performance," in ASME 2010 4th International Conference on Energy Sustainability, ES 2010, May 17, 2010 - May 22, 2010, Phoenix, AZ, United states, 2010, pp. 979-984.

[24] K. R. Campbell and D. J. Sailor, "Phase change materials as thermal storage for high performance homes," in ASME 2011 International Mechanical Engineering Congress and Exposition, IMECE 2011, November 11, 2011 November 17, 2011, Denver, CO, United states, 2011, pp. 809-818.

[25] American Society of Heating, Refrigerating, and Air-Conditioning Engineers (ASHRAE). 2009 ASHRAE Handbook: Fundamentals. Atlanta, GA: ASHRAE, 2009.

[26] D. G. Erbs, S. A. Klein, and J. A. Duffie, "Estimation of the diffuse radiation fraction for hourly, daily and monthly-average global radiation," Solar Energy, vol. 28, pp. 293-302, / 1982.

[27] United States Department of Energy (US DOE), "EnergyPlus Input Output Reference," ed, 2012.

[28] S. Behzadi and M. M. Farid, "Experimental and numerical investigations on the effect of using phase change materials for energy conservation in residential buildings," in Modeling high-performance buildings, 1791 Tullie Circle, NE, Atlanta, GA 30329, United States, 2011, pp. 366-376. 